\title{
Electron Microscope Study on the Innervation of Guinea Pig Liver - Proposal of Sensory Nerve Terminals in the Hepatic Parenchyme
}

\author{
Masako OHATA \\ Department of Anatomy (Prof. K. Uchida and Prof. T. ITo), Teikyo University School of Medicine, \\ Tokyo, Japan
}

Received June 4, 1983

Summary. Innervation of guinea pig livers was investigated by electron microscopy. Thinner unmyelinated autonomic nerves in the portal tract were found to contain many synaptic vesicles in their varicosities: small granular, agranular vesicles and a few large dense-cored vesicles, in addition to a few small mitochondria with sparse cristae, glycogen particles and occasional lysosomes. These adrenergic varicosities showed morphological signs suggesting emiocytotic release of transmitter substance through their naked surface into the portal space; they showed no synaptic contact with cells in the portal space. A cross section of a possible sensory nerve composed of several large axons filled with small mitochondria was identified in the portal space. Occasional large mitochondria-rich axon profiles, probably sensory in nature, were also present in the autonomic nerve. They seemed to be distributed in the hepatic parenchyme making large sensory terminals.

In the Disse's spaces thin autonomic nerves composed of varicose axons were observed. Here also, the varicosities contained synaptic vesicles with adrenergic characteristics. Some of them freely terminated in the Disse's space suggesting the release of transmitter substance into the space, but the majority of them made synaptic contacts with hepatocytes. Ito cells received relatively numerous synaptic contacts from the adrenergic terminals. The sinusoidal endothelial lining received no synaptic contacts but only nerve approaches over a wide distance ("synapses per distance"). The Kupffer cell infrequently sent a cy toplasmic process into the Disse's space to form a synaptic contact with an axon varicosity.

Presumed sensory terminals were characterized by their extraordinarily large sizes and by their contents of abundant small mitochondria with sparse cristae, glycogen particles and scanty small granular and agranular vesicles. These terminals closely contacted the Ito cell and/or hepatocy te.

In guinea pig liver, only adrenergic varicosities or terminals were identified in addition to probable sensory terminals.

Since the light microscopic study on the innervation of mammalian liver carried out by RIEGLE (1928) with the silver impregnation method, many investigations have been carried out to elucidate the nature of nerves supplying the liver with a variety of methods: not only electron microscopy but also histochemistry for cholinesterase, fluorescence method, autoradiography using ${ }^{3} \mathrm{H}$-noradrenalin, and chemical denervation of sympathetic nerves with 6-OH-dopamine (SUTHERLAND, 1964; UNGVÁRY and 
Donáth, 1969; Anufriew et al., 1973; Satler et al., 1974; SkaAring and Bierring, 1976; Forssmann and Ito, 1977; Uno, 1977; Reilly et al., 1978; Nobin et al., 1978; McCuskey et al., 1979; Sawchenko and Friedman, 1979). Yamada (1965), Ito and Shibasaki (1968) and TsUNEKI and IcHIHARA (1981) utilized transmission electron microscopy (TEM) to study the innervation of the liver in man, the monkey, mouse, several other mammals, birds and lower vertebrates. In the present study, the guinea pig liver has been examined by TEM, since it has been elucidated that in primates and guinea pigs, autonomic nerves are distributed not only in the periportal area but also in deeper parts of the hepatic lobules (Uno, 1977; McCuskey et al., 1979).

On the basis of the fine structural features of the axon terminals or varicosities, BuRnstock and IwAYAma (1971) and BuRnstock (1972) classified visceral nerves supplying the tubular organ provided with the smooth muscle layer into four groups: 1) Cholinergic axons which contain predominantly small $(30-60 \mathrm{~nm})$ agranular and a small proportion of large $(90-120 \mathrm{~nm})$ granular vesicles of unknown function. 2) Adrenergic axons which contain predominantly small $(30-60 \mathrm{~nm})$ granular and small agranular vesicles $(30-60 \mathrm{~nm})$ and some large $(90-120 \mathrm{~nm})$ granular vesicles the last of which are thought to take up monoamines. 3) Purinergic (non-adrenergic, noncholinergic) axons which contain predominant large (100-200 nm) granular vesicles greater than the large granular vesicles $(90-120 \mathrm{~nm})$ in the adrenergic and cholinergic axons and different from them by the absence of prominent electron transparent halo between the limiting membrane and the electron dense granular core. 4) Sensory axons which are characterized by numerous densely packed small mitochondria with only two cristae and a few small vesicles if any. According to the above authors, the purinergic axons are thought to represent inhibitory nerves for the smooth muscles, containing adenosine triphosphate (ATP) and other purine nucleotides as their transmitters. The sensory axon profiles have been observed in a variety of organs such as the gut, vas deferens, ureter and urinary bladder.

Peripheral synaptic terminals other than the above four types were described by Fujita and KoBayashi (1979) in their excellent electron microscopic work on the innervation of the dog pancreas. As is generally accepted, the synaptic clefts, i.e., close approaches of nerve terminals to effector cells, are on the order of $20 \mathrm{~nm}$, but the transmitter released from a distance as large as $120 \mathrm{~nm}$ is presumed to be effective, the effective cleft width appearing to be about $1 \mu \mathrm{m}$ (Burnstock and Iway ama, 1971). In his excellent TEM work on the innervation of the intestinal smooth muscle coat, YAMAмото (1977) introduced two modes of neuro-muscular connection: the close contact synapse along with the "synapse per distance" of JABONERO (1959). In the synapse per distance, the terminal portion of the autonomic nerves as a whole fulfils the role of the endings and releases, from its entire surface, messenger substances (mediators) which by diffusion reach across a certain distance to the effector cells (diffusion innervation of Yamauchi, 1964). Burnstock and Iwayama (1971) explained the mechanism of the synapse per distance as "en passage release of the transmitter" from varicosities in extensive terminal regions of the autonomic nerves.

\section{MATERIALS AND METHODS}

Five guinea pigs of both sexes were anesthetized with a mixture of $\alpha$-chloralose and urethane. After laparotomy, the liver was fixed by perfusion through the portal vein with a cold fixative containing a $2.5 \%$ glutaraldehyde and a $0.1 \mathrm{M}$ phosphate buffer at 
$\mathrm{pH} 7.4,0^{\circ} \mathrm{C}$. The liver was excised and thin tissue slices were cut, under a drop of fixative, into minute blocks. After $2 \mathrm{hr}$ fixation, they were rinsed several times in a cold $0.1 \mathrm{M}$ phosphate buffer containing $5 \%$ sucrose at $\mathrm{pH} 7.4$, and left overnight in the same buffer at $5{ }^{\circ} \mathrm{C}$. They were postfixed for $90 \mathrm{~min}$ by immersion in a solution of $1 \% \mathrm{OsO}_{4}$ in a $0.1 \mathrm{M}$ phosphate buffer $(\mathrm{pH} 7.4)$ at $0^{\circ} \mathrm{C}$. Following dehydration in graded ethanol, the tissues were embedded in Epon 812 and sectioned on a Porter-Blum Ultra-Microtome MT2-B. Ultrathin sections were stained with saturated uranyl acetate and Sato's lead solution. Micrographs were taken with a JEM-100C electron microscope.

\section{RESULTS}

\section{Nerves in the portal tract}

In the Glisson's sheath (portal tract) there are found a considerable number of unmyelinated axon bundles of variable thickness (Fig. 1,2). The majority of axons are separated from each other by thin Schwann cytoplasm, which appears more electron dense than the axoplasm. The surface of the nerve is completely or partly wrapped in a thin Schwann cytoplasm, but conspicuous mesaxons have occasionally been identified (Fig. 7). The Schwann cytoplasm contains cisternae of the rough endoplasmic reticulum, free polysomes, oval mitochondria, lysosomes, occasional multivesicular bodies and a Golgi complex. In a large nerve bundle, several Schwann nuclei can be detected on one section plane (Fig. 1).

As seen in Figure 1, such larger nerve bundles, in which the axoplasm of almost all axons are packed merely

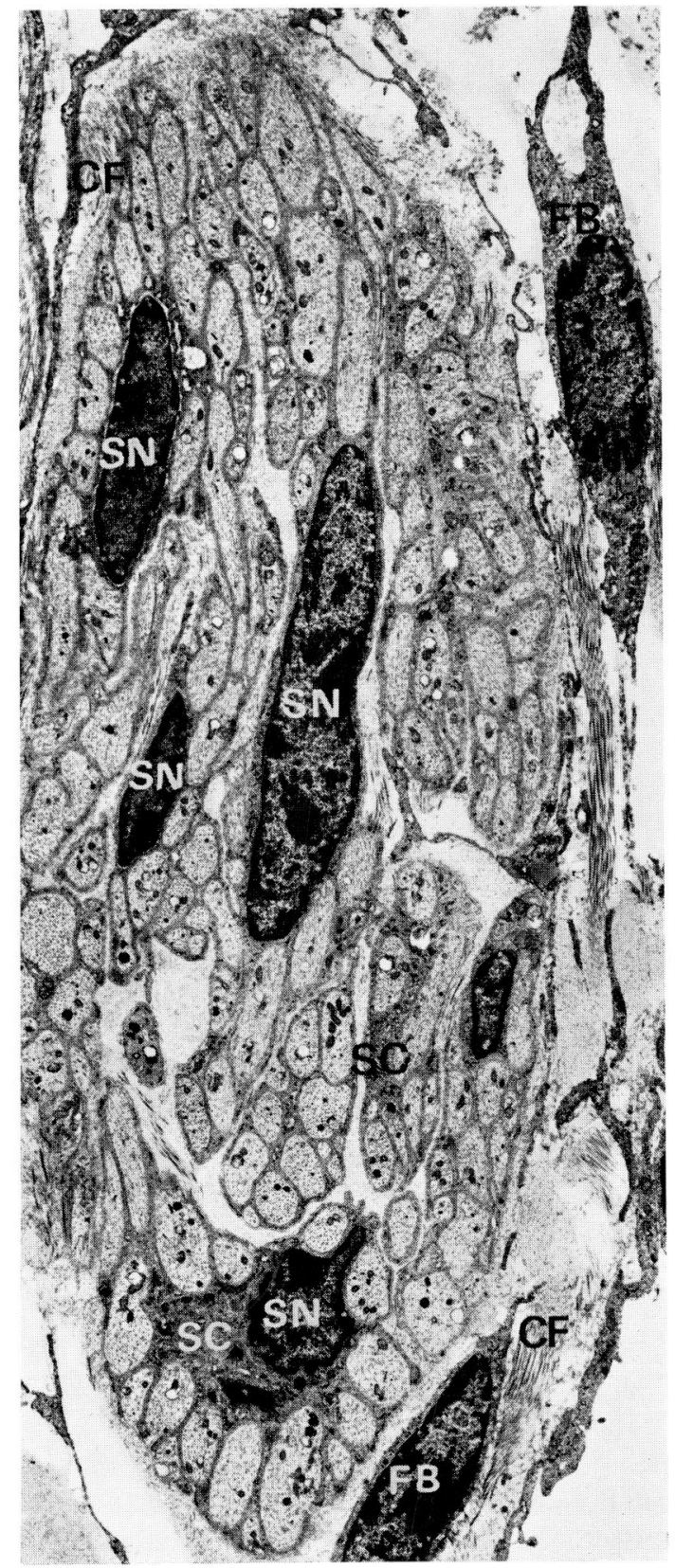

Fig. 1. An oblique section of a large autonomic nerve containing five Schwann cell nuclei (SN). The Schwann cytoplasm ( $S C$ ) is more electron dense than the axoplasm. The axons show no vesiculate varicosities. $F B$ fibroblast, $C F$ collagen fibers. $\times 4,800$ with abundant micro(neuro)tubules, sparse mitochondria smaller than those of the Schwann cytoplasm, glycogen $\beta$-particles and lysosomes can be found. These axons 


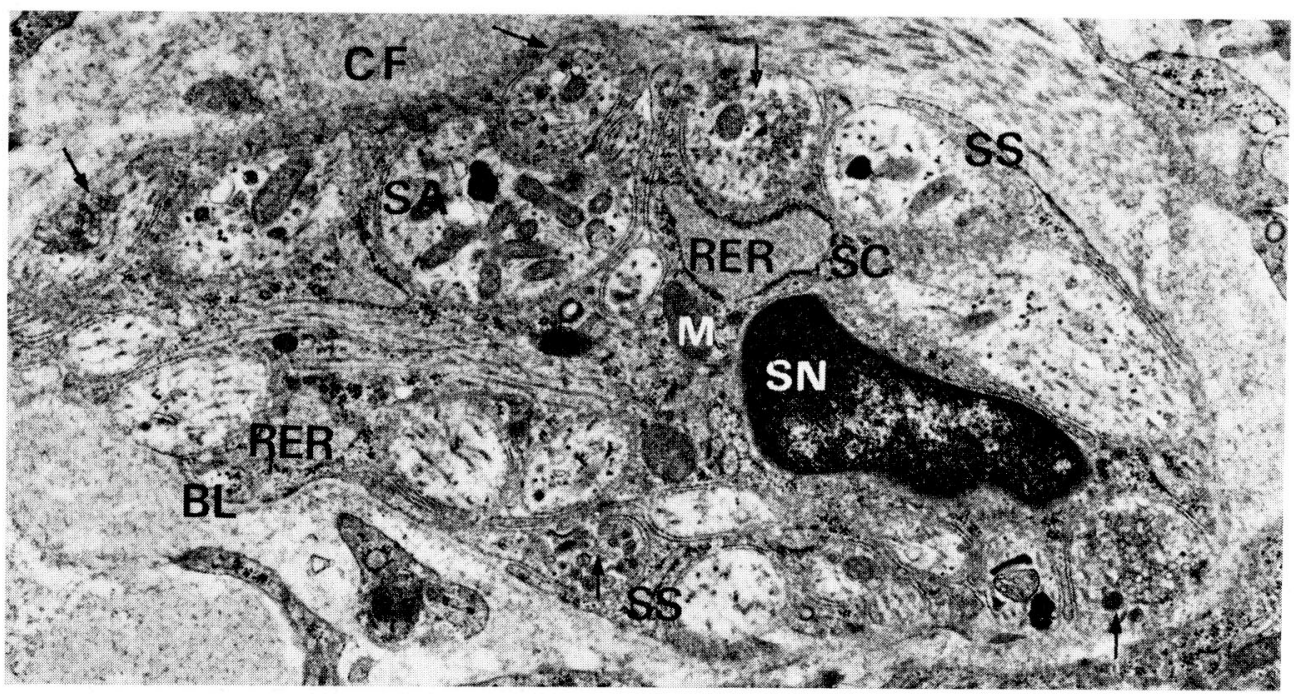

Fig. 2. An oblique section of a small autonomic nerve in the portal space. Several vesiculate varicosities (arrows) of the axons have naked surfaces facing the portal space. Among the autonomic axons a large presumably sensory axon profile ( $S A$ ) characterized by numerous small mitochondria and a lysosome is seen. $B L$ basal lamina, $C F$ collagen fibers, $M$ large mitochondria in Schwann cytoplasm, RER cisternae of the rough ER, SC Schwann cytoplasm, $S N$ Schwann nucleus, SS Schwann sheath. $\quad \times 16,800$

do not show any varicosities containing synaptic vesicles. In smaller nerve bundles depicted in Figures 2, 3 and 4, are found, besides relatively small axon profiles containing only numerous microtubuli and sparse mitochondria, large ones containing in addition a variable number of synaptic vesicles, mixed in different proportions. This finding suggests that the small nerves are varicose axons consisting of alternating large vesiculate swellings and thinned portions which contain only microtubuli and sparse mitochondria. The cross section of such nerves discloses small profiles of the attenuated portions and large profiles of vesiculate varicosities mixed in variable proportions (Fig. 2-4). The majority of the vesiculate varicosities expose their naked surface to the portal space, which is covered only with the basal lamina, investing the entire surface of the nerves. As seen in Figures 2, 3 and 4, vesiculate varicosities contain, besides microtubules, glycogen particles and mitochondria, synaptic vesicles of an adrenergic composition, i.e., numerous small agranular as well as granular vesicles about $20-60 \mathrm{~nm}$ in diameter and also large dense-cored vesicles about 70-90 $\mathrm{nm}$ in diameter, though in a smaller proportion. They are concentrated in the outer area of the axoplasm tending toward the naked surface, and some vesicles approach the plasma membrane to anchor thereon, thus suggesting the emiocytotic release of the transmitter. In the majority of cases, the small agranular vesicles seem more or less predominant over the small granular. This tendency is clearly seen in the vesiculate varicosity in Figures 2 and 3. They might be mistaken for the cholinergic terminals if a few small granular vesicles were overlooked. Among numerous small agranular vesicles seen in the vesiculate varicosities of the nerve in Figure 4 and in its inset, a considerable number of flat or elongate agranular ones are intermingled. The mechanism which may be responsible for the morphological variability of the small agranular vesicles is unknown.

In Figure 5, a small nerve bundle sectioned nearly longitudinally is visible in the 
portal tract, which is composed of a small number of varicose axons disposed in parallel fashion. Numerous spindle-shaped varicosities are closely arranged along the long axis of the nerve bundle. Between the varicose axons, Schwann cytoplasmic sheets are interposed, but the surfaces of the nerve bundle facing the connective tissue are devoid of this sheath and merely enveloped with a basal lamina. The varicosities contain a variable number of synaptic vesicles, sparse mitochondria, occasional glycogen $\beta$-particles and microtubules. The majority of them exhibit a naked surface facing the connective tissue, toward which small synaptic vesicles are clustered. Some even appear to approach the plasma membrane to anchor on it, suggesting the emiocytotic release of the transmitter substance into the connective tissue (Fig. 5, 6). As observed in the above mentioned small nerve in the portal tract, the total naked area of numerous vesiculate varicosities facing the connective tissue is thought to be of considerable extent. Thus, it appears that the small nerves in their course through the portal tract might have a considerable large secretory surface for releasing transmitter substances to the connective tissue. In the present study, however, no synaptic connections between the vesiculate varicosities and other cell types have been recognized anywhere.

In the present study, the author has encountered in a portal tract of the guinea pig liver a cross section of an unusual nerve bundle which is composed of extraordinarily large

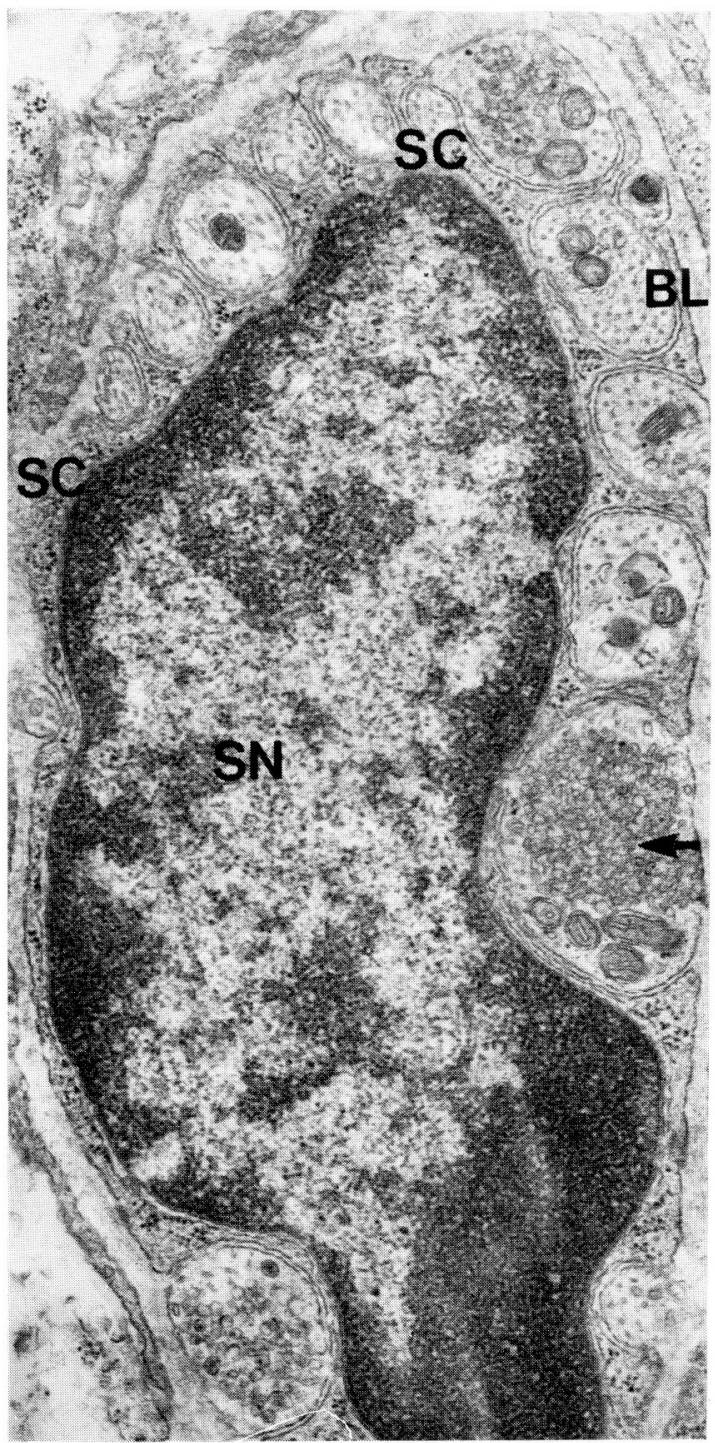

Fig. 3. A cross section of a small nerve in the portal space. Three vesiculate varicosities of axons expose their naked surfaces to the portal space, and many small agranular and granular vesicles are concentrated toward the naked surface, some of them being attached to the plasma membrane. In the largest varicosity (arrow), agranular vesicles strikingly predominate over the granular ones. $B L$ basal lamina, SC Schwann cytoplasm, SN Schwann nucleus. $\times 25,000$ transections of axons $2.5 \mu \mathrm{m}$ in diameter on an average densely packed by abundant small mitochondria mingled with a variable number of small lysosomes. This nerve bundle was invested almost completely with the Schwann sheath accompanied by a basal lamina, and several short mesaxons were detected here and there. In the thick 


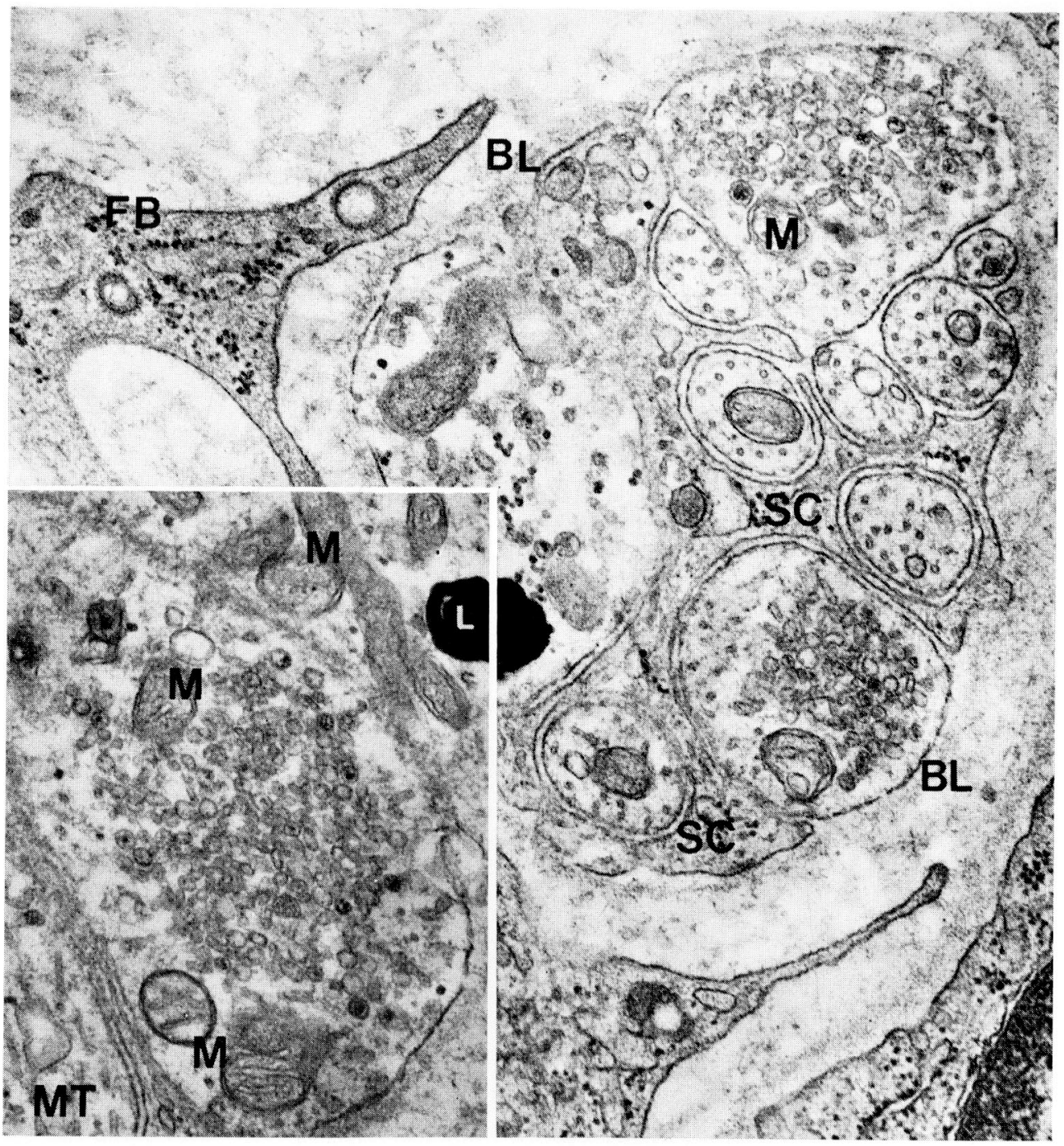

Fig. 4. A cross section of a small nerve in the portal space. Two large varicosities expose their naked surfaces to the portal space. Small synaptic vesicles tend to accumulate toward the naked surface facing the portal space, and some of them rest on the plasma membrane. $B L$ basal lamina, $F B$ fibroblast, $M$ small mitochondria in axons, $S C$ Schwann cytoplasm. $\times 42,400$ Inset. A large vesiculate varicosity. Among agranular vesicles many flat or elongated ones are intermingled. $L$ lysosome, $M$ small mitochondria in axons, $M T$ microtubules. $\times 42,400$

crescent-shaped Schwann cytoplasm covering the left boundary of this nerve bundle, one can observe conspicuously numerous cisternae of the rough endoplasmic reticulum (RER), free polysomes and mitochondria larger than in the axoplasm (Fig. 7). The mitochondria-rich large axons or varicosities contain a variable number of dense bodies, probably lysosomes, which for unknown reasons exhibit an inverse proportion to that of the mitochondria. The electron lucent axoplasm contains, besides mitochondria and lysosomes microtubules and occasional large dense-cored vesicles; small synaptic vesicles are hardly found. Several small autonomic axon profiles $(780 \mathrm{~nm}$ in diameter on 
an average) are scattered along the surface of the right half of this nerve, and among them, only one vesiculate varicosity is visible. A large irregularly shaped axon profile occupying the wide left third of this nerve shows a moderately electron dense axoplasm packed with microtubules, with a considerable number of small mitochondria loosely scattered throughout the wide axoplasm.

Seen in the midst of the upper border of the nerve bunble in Figure 2, is a large axon profile characterized by numerous small, loosely disposed mitochondria with sparse cristae, along with a few small vesicles, glycogen $\beta$-particles and a lysosome. The surface of this large axon profile is not directly exposed to the portal space.

As is widely known, mast cells been encountered (Fig. 8) which are characterized by numerous coarse granules of variable electron density are often encountered in the connective tissue of the portal tract.

\section{Nerves in the Disse's space}

Figure 9 represents a thin nerve branch, composed of a few varicose axons, sectioned nearly longitudinally, and running in the Disse's space closely along the microvilli-devoid sinusoidal surface of a hepatocyte. This nerve branch is, incompletely wrapped in Schwann sheath, characterized by large mitochondria and free polysomes. Along its course, several vesiculate varicosities, mostly bearing small mitochondria in addition to vesicles, are detectable. One of them is shown in a higher magnification in the inset of Figure 9. It contains many small agranular, granular vesicles and a few large granular ones, showing an adrenergic veiscular composition. These vesicles are concentrated toward the naked surface facing the Disse's space without making contact with other cell types; it may then be presumed that the transmitter substance can be released directly into the Disse's space. The free surface of these nerve bundles, including the naked varicosities, usually lacks the basal lamina regardless of the presence or absence of the Schwann sheath

Fig. 5. A nearly longitudinal section of a small nerve in the portal space. Many vesiculate axon varicosities (arrows) expose their naked surfaces to the portal space and small agranular and granular vesicles tend to concentrate near the naked surfaces, some approaching the latter to be attached to the plasma membrane. $C F$ collagen fiber, $F B$ fibroblast. $\times 13,200$

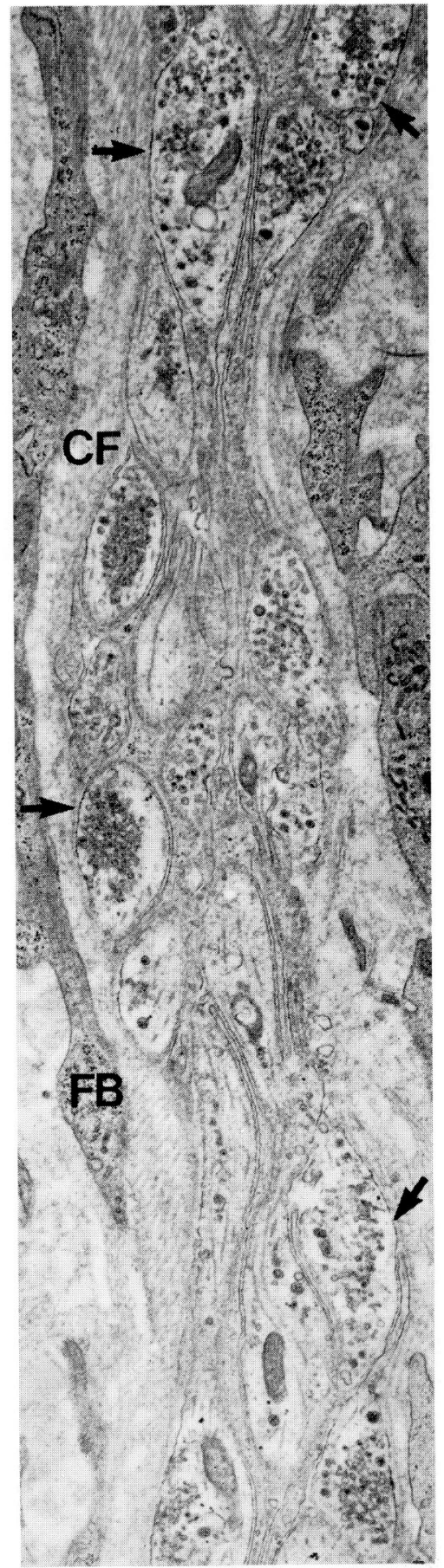




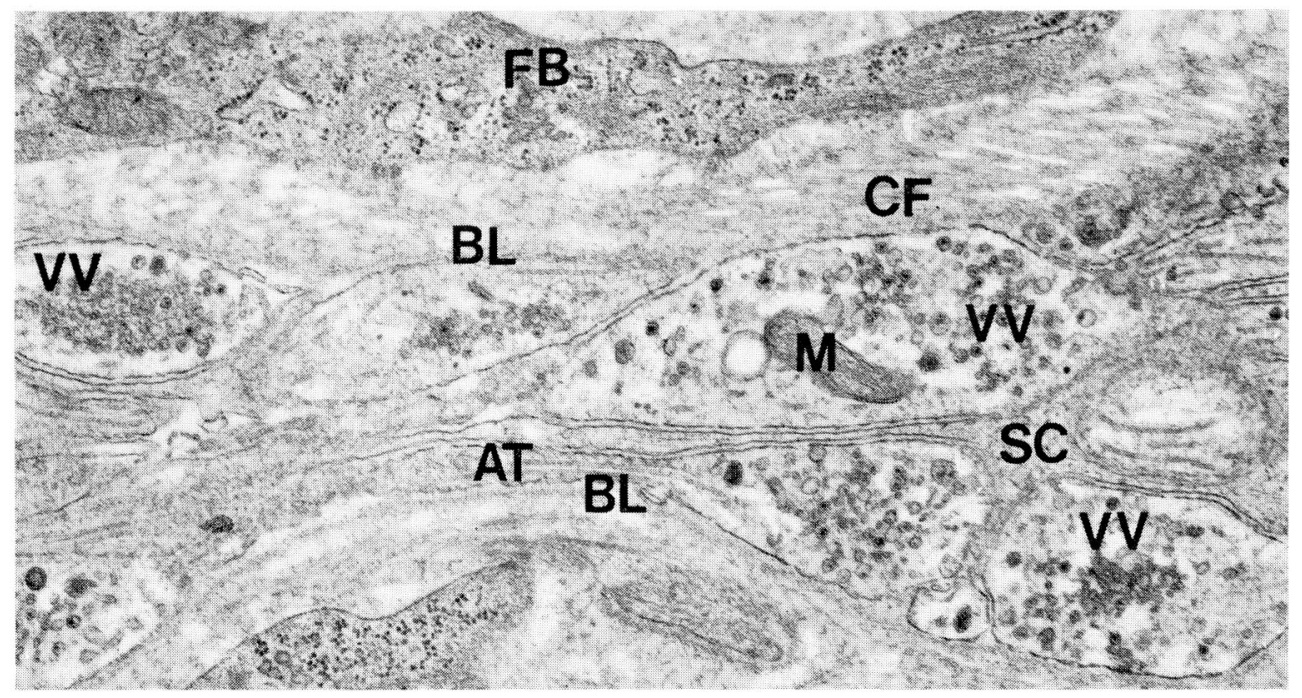

Fig. 6. A higher magnification of a part of the small nerve depicted in Figure $5 . \quad A T$ attenuated portion of axon, $B L$ basal lamina, $C F$ collagen fiber, $F B$ fibroblast, $M$ small mitochondria, $S C$ Schwann cytoplasm, $V V$ vesiculate varicosities. $\quad \times 21,800$

when they are located at a certain distance away from the portal tract. A nearly lengthwise sectioned fine nerve composed of two varicose axons as depicted in Figure 10 , is devoid of the Schwann sheath. The vesiculate varicosity of the upper axon contains an accumulation of adrenergic synaptic vesicles besides several small elongate mitochondria clustered along the bottom surface. The accumulation tends to form toward the convex upper half of this varicosity which is closely fitted to a depression of the adjacent hepatocyte, probably making a synaptic contact across a synaptic cleft about $20 \mathrm{~nm}$ in width. Another subjacent varicose axon has two vesiculate varicosities both with a convex bottom surface. One of them, standing on the left side, contains a small number of adrenergic vesicles in its convexity, and seems to make synaptic contact with a subjacent RER-rich cytoplasmic mass, probably of a fat-storing cell (Ito cell) in the Disse's space. In the other varicosity on the right side, adjacent to the above-mentioned, small agranular and granular vesicles are accumulated in a half of the convex bottom, which makes a close synaptic contact with the subjacent hepatocyte.

Figure 11 represents an extraordinarily large irregular-shaped vesiculate varicosity about $2,000 \mathrm{~nm}$ in diameter incompletely enveloped by Schwann cytoplasm devoid of the basal lamina. The extraordinary varicosity is characterized by an irregular cluster of numerous mitochondria with scanty cristae. Among the mitochondria many glycogen $\beta$-granules are scattered, and an accumulation of scanty small agranular, granular (about $58 \mathrm{~nm}$ in diameter) and a few large granular vesicles $(90 \mathrm{~nm}$ in diameter) are observed. This large vesiculate varicosity in the Disse's space closely abuts on the perisinusoidal surface of a Kupffer cell, but it is separated from the latter by a Schwann cytoplasm, so that it makes no synaptic contact with the cell.

A short nerve bundle composed of several axons is seen in the Disse's space close to the portal tract (Fig. 12). A small vesiculate varicosity containing several large granular, some small granular and agranular vesicles as well as glycogen $\beta$-particles occupies the innermost part of the nerve bundle, abutting with its flat surface on the sinusoidal endothelial lining across a relatively wide cleft. In the midst of the cleft, 


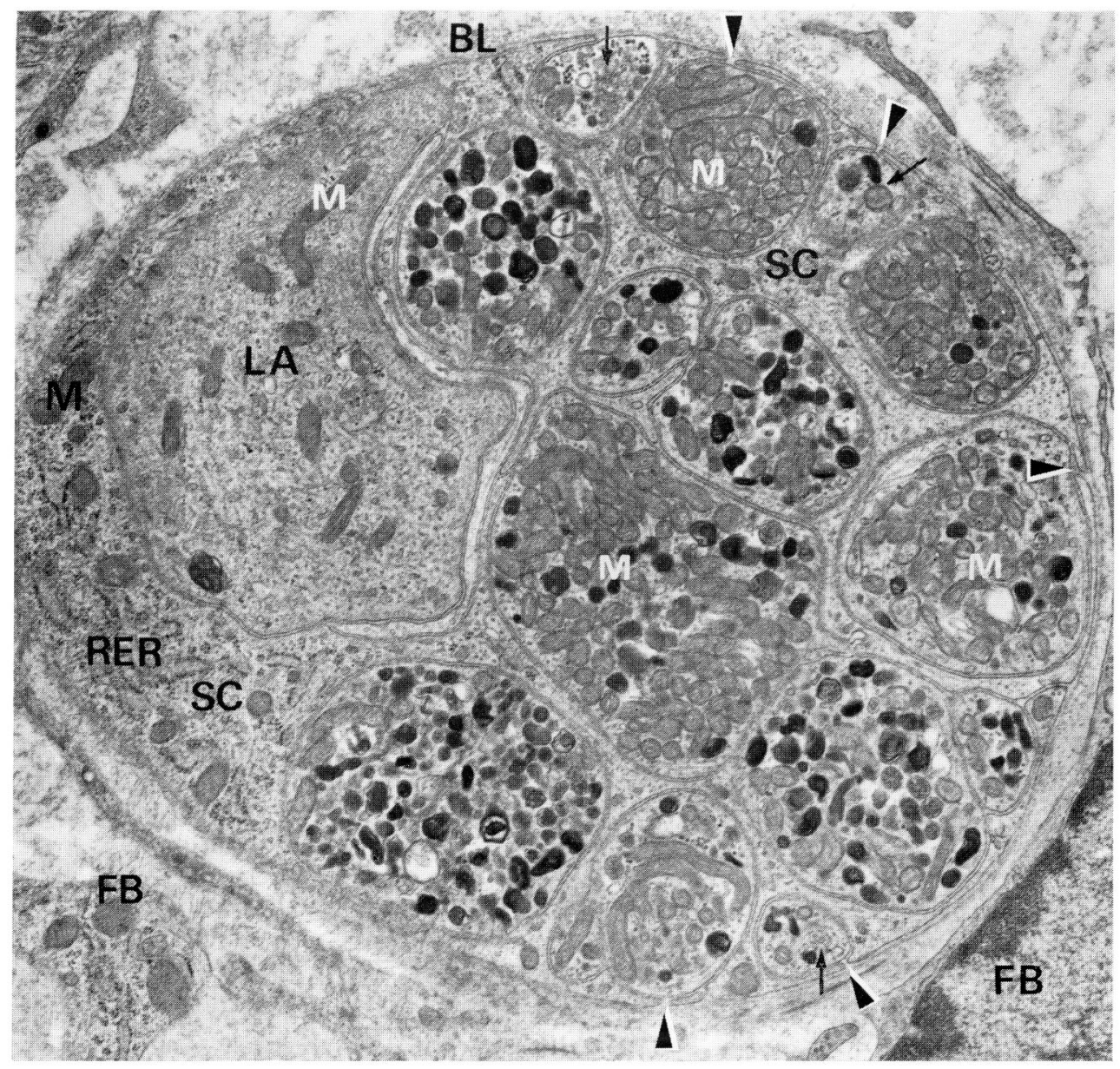

Fig. 7. A cross section of a nerve composed of large, unmyelinated, possibly sensory axons packed by abundant small mitochondria. Some of them contain a variable number of small dense bodies (lysosomes) in inverse proportion to the mitochondria. Some small autonomic axons (arrows) are found along the outline which is almost completely wrapped in a Schwann sheath, occasionally showing short mesaxons (arrowheads). $B L$ basal lamina, $F B$ fibroblast, $L A$ large irregular-shaped axon profile, $M$ mitochondria, RER rough-ER, SC Schwann cytoplasm. $\times 15,300$

about $120 \mathrm{~nm}$ in width, a basal lamina is observed. A synaptic contact between the vesiculate varicosity and the sinusoidal endothelium may be expected ("synapse per distance"). Further, a cross section of a small axon bundle observed in the Disse's space, shows a free vesiculate varicosity, containing adrenergic synaptic vesicles besides sparse small mitochondria is remarked on the right side (Fig. 13). Into this axon bundle, a Kupffer cell situated in the sinusoidal lumen on the upper left side protrudes a clubbed process containing dense bodies and free ribosomes. The flat surface of the thickened end of this process is apposed almost parallel to the corresponding surface of an adjacent axon varicosity across a cleft about $60 \mathrm{~nm}$ in width. In view of this finding, we may suppose the existence of a synaptic contact between a cytoplasmic process of the Kupffer cell and the autonomic nerve, although on this section plane 


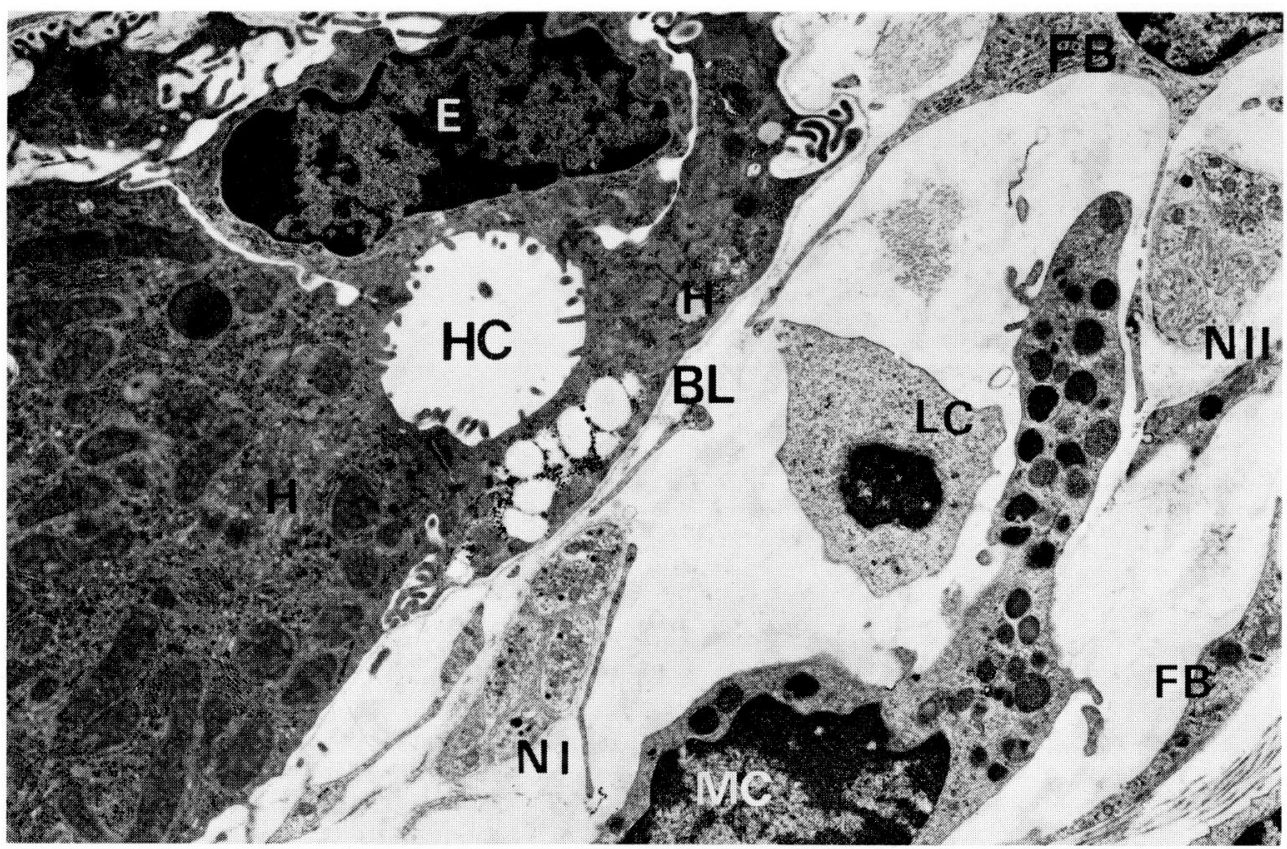

Fig. 8. A portion of the portal space, in which a Hering's canal $(H C)$, a mast cell $(M C)$, small nerves ( $N I$ and $N I I$ ), fibroblasts $(F B)$ and lymphocyte $(L C)$ are seen. $B L$ basal lamina, $E$ epithelial cell, $H$ hepatocyte. In $N I$ and $N I I$, are seen vesiculate varicosities with their naked surface facing the portal space. $\times 8,000$

only a part of the axon varicosity lacking synaptic vesicles is visualized.

The nucleated portion of the Schwann cell is seldom encountered in the Disse's space of the guinea pig liver. Figure 14 shows an example, sandwiched between two sinusoids. The Schwann cell has scanty cytoplasm, which is characterized by welldeveloped cisternae of the rough endoplasmic reticulum, many free polysomes and a large mitochondrion. Around the nucleus with a large nucleolus, varicose axon profiles are aligned along the bottom surface of the nucleus, fitting to indentations induced on the cytoplasm. Along the bottom surface of the attenuated left part of the nucleus, two axons with vesiculate varicosities are elongated in parallel to each other. The vesiculate varicosities contain adrenergic synaptic vesicles besides sparse mitochondria and glycogen $\beta$-particles. Of the two large varicosities, the one on the left side is rich in small granular vesicles and its naked surface abuts on the sinusoidal endothelial lining as if to make a synaptic contact across a cleft as wide as about $1 \mu \mathrm{m}$ ("synapsis per distance"); the accurate distance is obscure, since a part of the plasma membrane limiting the varicosity is artificially destroyed. The other vesiculate varicosity near the nucleus shows no free surface exposed to the Disse's space.

\section{Nerve endings close to hepatocytes and sinusoidal cells}

Most numerous naked axon terminals are detectable along the perisinusoidal surface of the hepatocyte, and they tend to diminish toward the central portion of the lobules. Not only one, but also two vesiculate varicosities or terminals are often revealed per one hepatocyte (Fig. 15). The two varicosities are juxtaposed and are fitted alike to corresponding depressions on the perisinusoidal surface of the hepatocyte, across a 


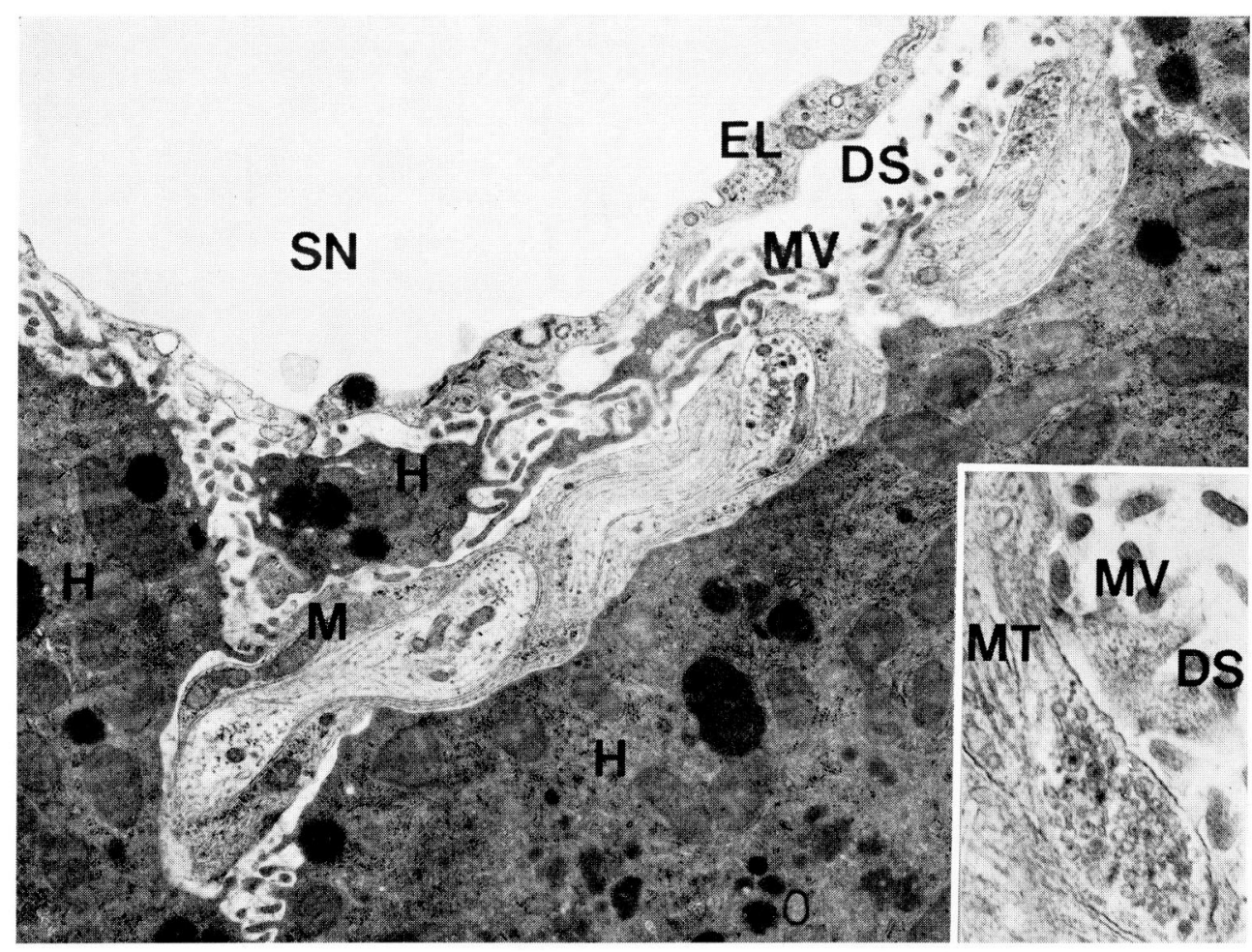

Fig. 9. A small, nearly longitudinally sectioned nerve composed of a few varicose axons running in the Disse's space. Vesiculate varicosities contain small mitochondria and vesicles. The Schwann sheath is characterized by large mitochondria $(M)$ and devoid of a basal lamina, $D S$ Disse's space, $E L$ endothelial lining, $H$ hepatocyte, $M V$ microvilli, $S N$ sinusoid. $\times 10,000$. Inset. One of the vesiculate varicosities is filled with small agranular and granular vesicles as well as large granular ones. Its naked plasma membrane directly faces the Disse's space (DS). $\quad M V$ microvilli, $M T$ microtubules. $\times 25,000$

synaptic cleft about $20 \mathrm{~nm}$ in width. In the bottom varicosity, numerous adrenergic synaptic vesicles are concentrated toward the hepatocyte, suggesting the adrenergic innervation of the hepatocyte. In the upper varicosity, however, besides one vesiculate protrusion which extends into an indentation on the hepatocyte forming an adrenergic synapse, another, containing adrenergic synaptic vesicles, extends into the Disse's space to terminate at a place far from the endothelial lining. The two vesiculate protrusions are separated from each other by an axoplasmic layer containing microtubules. Thus, it is presumed that the transmitter substance may be released from the latter into the Disse's space to permeate it by diffusion.

Two indentations induced at a short intervals on the perisinusoidal surface of a hepatocyte are shown to contain corresponding vesiculate varicosities (Fig. 16). Both varicosities are regarded on the basis of the nature of their synaptic vesicles as adrenergic and are juxtaposed to a hepatocyte across a synaptic cleft about $28 \mathrm{~nm}$ in width. In contrast to the synaptic vesicles in the right varicosity $(1.1 \mu \mathrm{m}$ in diameter), which are rather concentrated toward the hepatocyte, those in the left (1.3 $\mu \mathrm{m}$ in diameter) are accumulated toward the free surface exposed directly to the perisinusoidal space, while the opposite side facing the hepatocyte is for the most part occupied by mitochondrial cluster. Thus, from the left varicosity the transmitter substance is presumed 


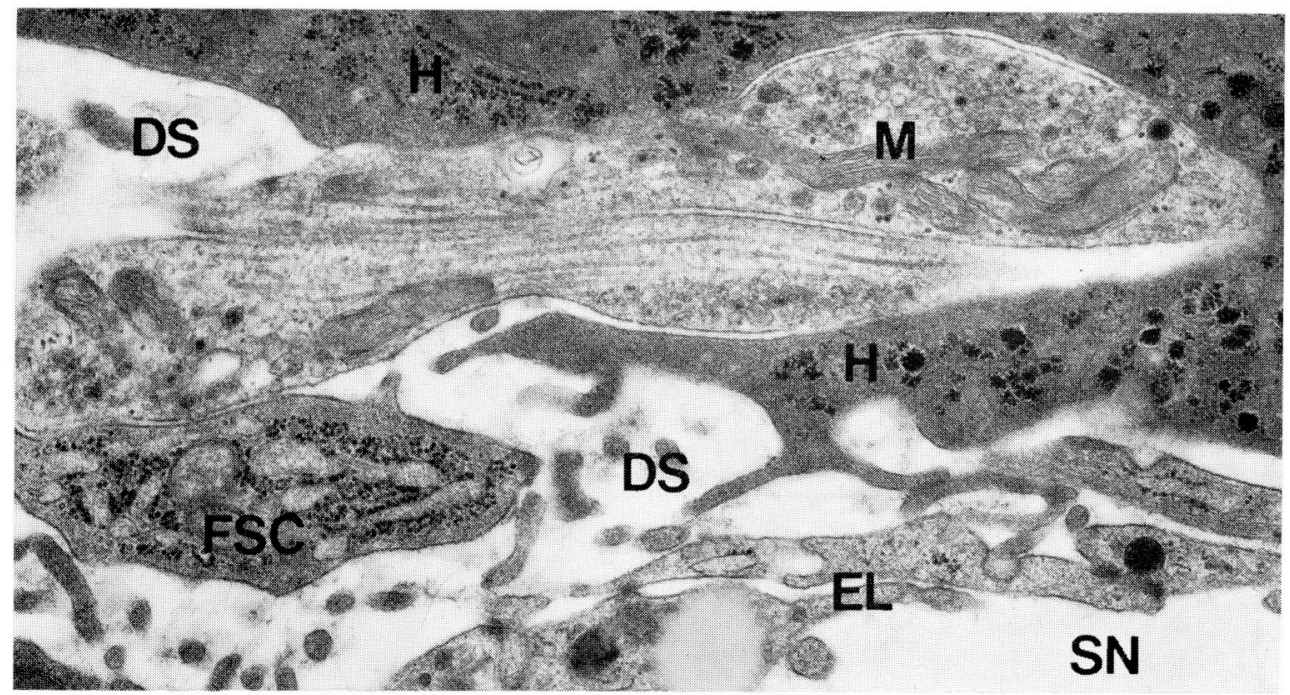

Fig. 10. A lengthwise sectioned nerve composed of two varicose axons. The varicosity of the upper axon makes a synaptic contact with a hepatocyte $(H)$. The bottom axon shows two vesiculate varicosities: one located on the left side makes a synaptic contact with an Ito cell (FSC) and the other on the right side with the hepatocyte ( $H$ ). DS Disse's space, EL endothelial lining, $M$ mitochondria, $S N$ sinusoid. $\times 25,000$

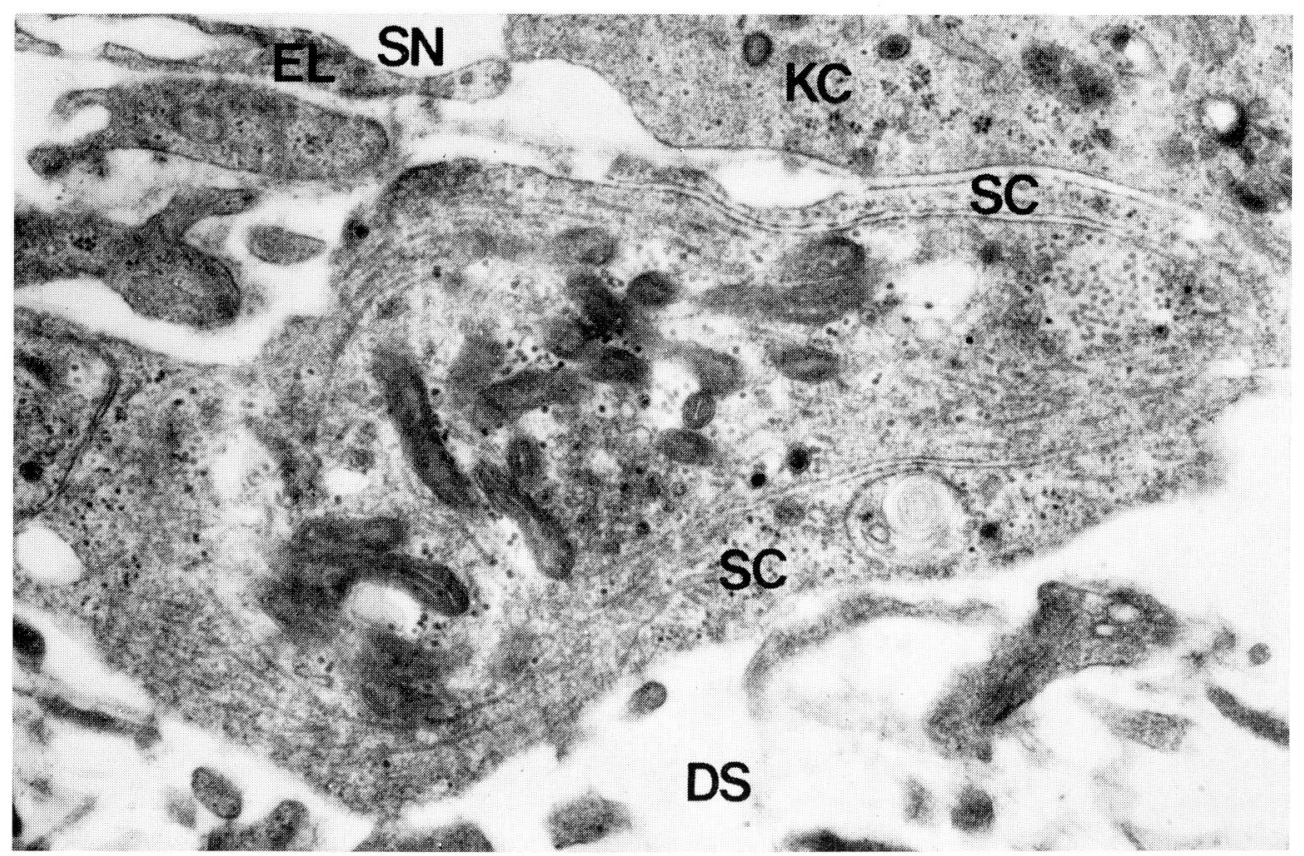

Fig. 11. An extraordinarily large, irregular-shaped varicosity wrapped in the Schwann cytoplasm (SC), containing a cluster of small irregular-shaped mitochondria with sparse cristae, small numbers of small agranular and granular vesicles, a few large granular vesicles and glyco. gen particles. This varicosity in the Disse's space (DS) makes no synaptic contact with the abutting cells. EL endothelial lining, $K C$ Kupffer cell, $S N$ sinusoid. $\quad \times 26,000$ 
to be released into the Disse's space as supported by the finding of the free vesiculate protrusion described above.

A probably adrenergic vesiculate varicosity shown in Figure 17 is completely embedded in the hepatocyte making a synapsis with the latter, although the width of the synaptic cleft is difficult to measure except in its upper short extent ( $25 \mathrm{~nm}$ in width). This intrahepatocytic varicosity (1.2 $\mu \mathrm{m}$ in diameter) is densely packed by small granular and agranular vesicules. Especially intermingled among small agranular vesicles are sparse flattened ones. The electron dense core of the large granular vesicles is not conspicuous. On this section plane, mitochondria are not encountered in the terminal.

Vesiculate terminals making synaptic connections with Ito cells in the Disse's space have not infrequently been encountered as already shown in Figure 10. A moderately large typical adrenergic terminal $(1.5 \mu \mathrm{m}$ in diameter) is observed in Figure 18 making synaptic connection with the cytoplasmic segment of an Ito cell. In this ovoid varicosity, the surface directed toward the hepatocytes is partly invested with a thin Schwann cytoplasm, whereas the opposite sinu-

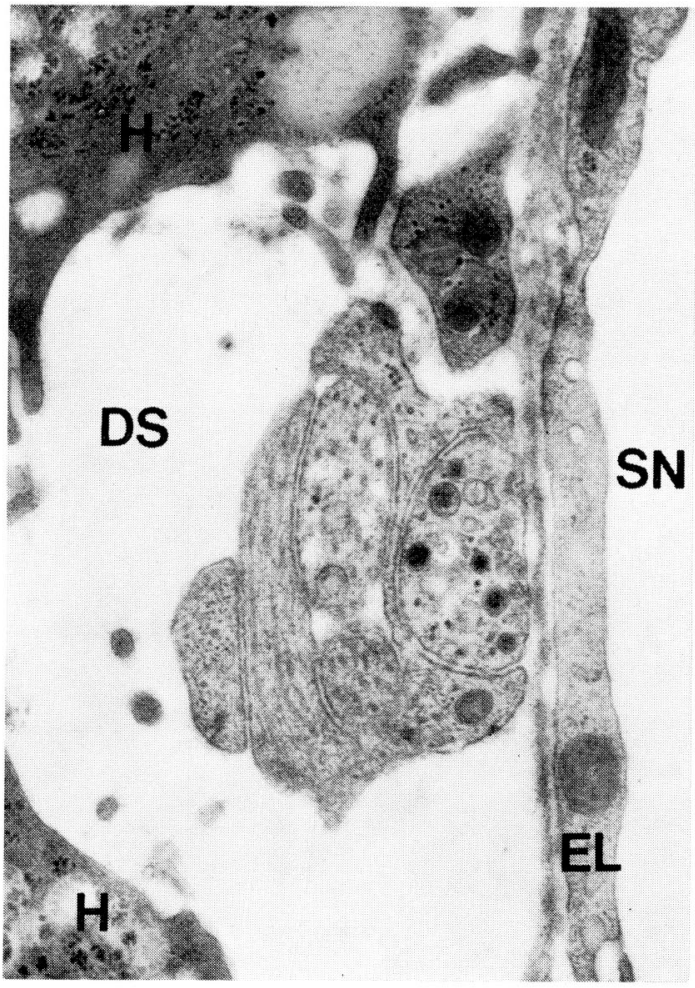

Fig. 12. A section of a small nerve in the Disse's space (DS). The innermost axon varicosity, containing several large dense-cored vesicles and a few small granular and agranular ones as well as glycogen particles, directly faces the endothelial lining ( $E L)$ of the sinusoid (SN) across a $120 \mathrm{~nm}$ wide cleft (synapse per distance), in the midst of which a basal lamina is observed. $H$ hepatocyte. $\times 25,000$ soidal surface forms a close synaptic contact with an Ito cell across a cleft about 27$38 \mathrm{~nm}$ in width. This varicosity contains, besides adundant adrenergic synaptic vesicles, relatively numerous small mitochondria which are gathered for the most part on the right side while numerous small vesicles are concentrated in the opposite part, juxtaposed to the synaptic membrane.

Figure 19 represents a large mitochondria-rich varicosity measuring about $1.7 \mu \mathrm{m}$ in diameter. This varicosity in the Disse's space makes a close contact not only with an adjacent empty Ito cell, but also with a hepatocyte on the upper left surface across a $20 \mathrm{~nm}$ wide cleft. This vacuolar varicosity of an extraordinary large caliber is characterized by numerous small round mitochondria with sparse cristae loosely scattered in the axoplasm and a considerable amount of dispersed glycogen $\beta$-particles making irregular clusters throughout the axoplasm. In contrast to rich mitochondria, synaptic vesicles are not numerous; the small granular and agranular ones (about $40 \mathrm{~nm}$ in diameter) are scattered throughout the axoplasm, intermingled with some large dense cored one (about $90 \mathrm{~nm}$ ). Small granular vesicles, however, make a small cluster shifted towards the Ito cell. In the present study, another similarly large varicosity has 


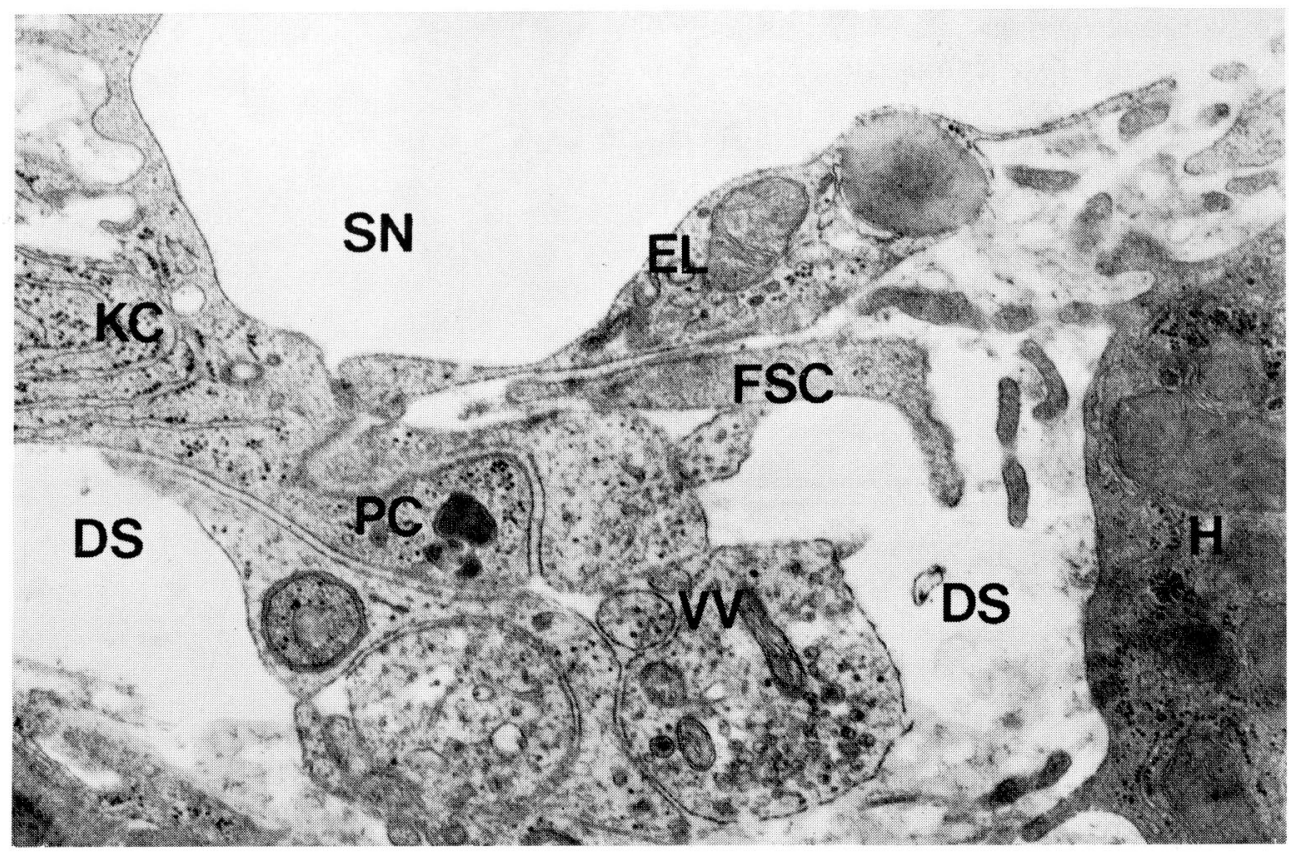

Fig. 13. Synaptic connection between a nerve in the Disse's space (DS) and a clubbed cytoplasmic process $(P C)$ protruding from a Kupffer cell $(K C)$ into the Disse's space. Note a synaptic cleft, about $60 \mathrm{~nm}$ wide. $E L$ endothelial lining, FSC subendothelial process of an Ito cell, $H$ hepatocyte, $S N$ sinusoid, $V V$ free vesiculate varicosity. $\quad \times 25,000$

been revealed, making a close contact with an Ito cell, in which, however, synaptic vesicles, were too few to be identified among the scattering mitochondria. Furthermore, a varicosity of the like characteristic $(1.7 \mu \mathrm{m}$ in diameter $)$ which makes a close contact across a $20 \mathrm{~nm}$ wide cleft with a hepatocyte has been revealed in the present study (Fig. 20). The internal fine structures of this large size varicosity generally agree with those of the varicosity depicted in Figure 19. These large, mitochondriarich varicosities remind the present author of a similar axon profile in an autonomic nerve of the portal space (Fig. 2).

A vesiculate varicosity was found in the Disse's space (Fig. 21) to be apposed, with its convex surface, to a concavity on the sinusoidal surface of an Ito cell. Nevertheless, a synaptic connection between the varicosity and the Ito cell can hardly by expected, because the axoplasmic area close to the Ito cell is occupied by numerous small mitochondria and vacuoles, while abundant small granular and agranular synaptic vesicles are concentrated in the opposite area, facing the sinusoidal endothelial lining across a 64-120 nm wide cleft. As some small synaptic vesicles lie closely to the plasma membrane of the axon, this adrenergic varicosity $(1.3 \mu \mathrm{m})$ and the endothelial lining make a "synapse per distance" (diffusion innervation, YAmauchi, 1964). Another small adrenergic varicosity containing sparse synaptic vesicles exhibits a synaptic connection with the upper left surface of this Ito cell.

There are often varicosities or terminals of ordinary sizes containing a number of small mitochondria occupying their major areas and usually sparse synaptic vesicles (Fig. 22a, b). These mitochondria-filled terminals $(1.2 \mu \mathrm{m}$ and $1.1 \mu \mathrm{m})$ may possibly represent pictures of ordinary vesiculate varicosities sectioned along the planes passing 


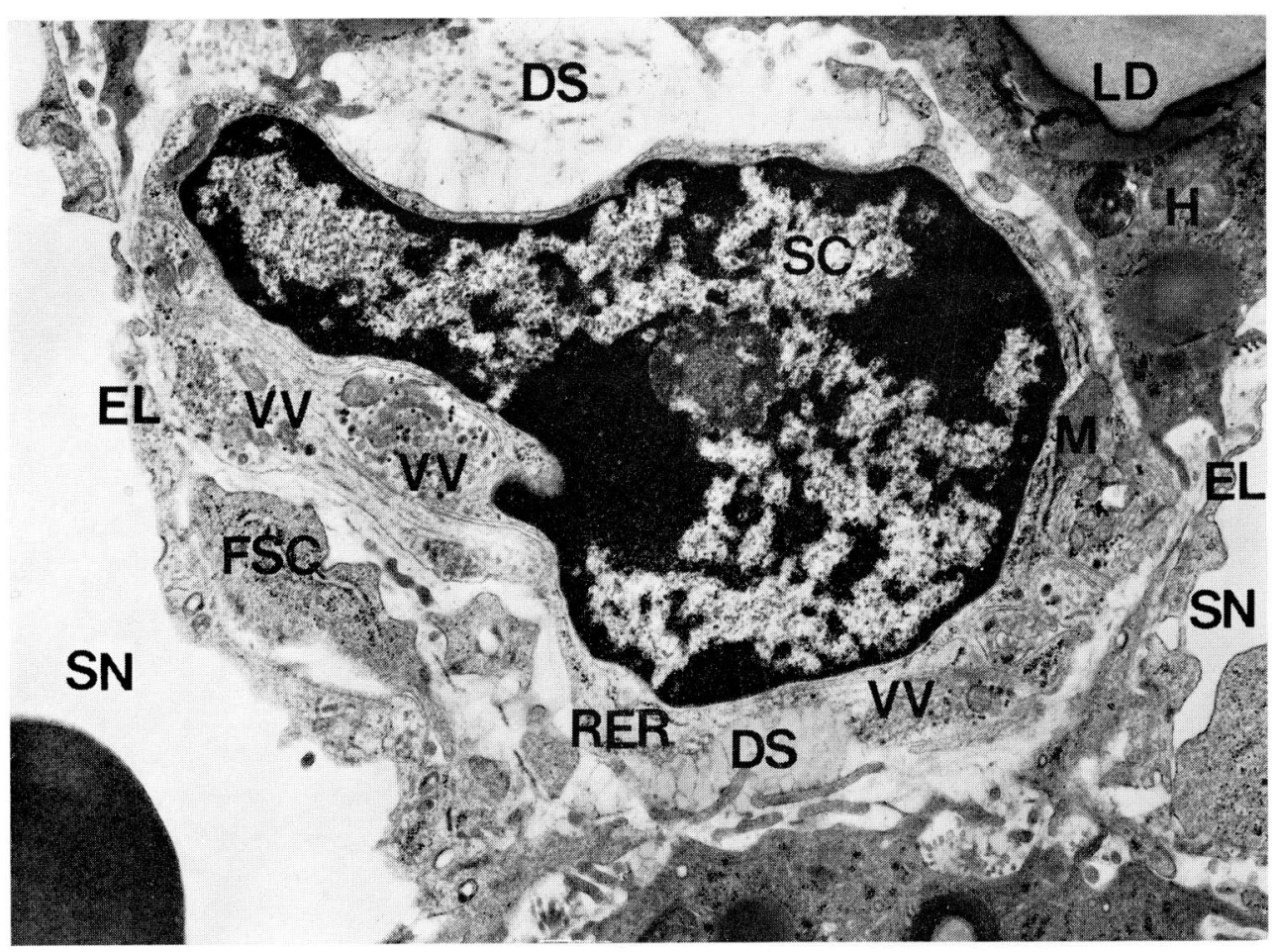

Fig. 14. Nucleated portion of a Schwann cell (SC) in the Disse's space (DS), sandwiched between two sinusoids ( $S N)$. The Schwann cytoplasm, characterized by large mitochondria $(M)$, cisternae of rough ER (RER) and ribosomes, embraces vesiculated varicosities (VV) and attenuated portions of axons. A large vesiculate varicosity on the left seems to make a "synapse per distance" with the endothelial lining (EL) of the sinusoid. FSC Ito cell, H hepatocyte, $L D$ lipid droplet. $\quad \times 13,000$

through the portion containing numerous mitochondria. As seen in Figures 18 and 21, the guinea pig livers not rarely exhibit such varicosities, in which considerable numbers of small mitochondria are concentrated in one pole of the varicosities, whereas synaptic vesicles are clustered on the opposite pole.

Two cases of extraordinary large varicosities (Fig. 23, 24) possessed, in contrast to sparse small agranular and granular vesicles, abundant small mitochondria (over twenty) even far exceeding those in the above small varicosities rich in mitochondria (Fig. 22a, b). The varicosity $(1.8 \mu \mathrm{m}$ in diameter) in Figure 23 is in a close connection across a $20 \mathrm{~nm}$ wide cleft with an Ito cell. Abundant small mitochondria are concentrated in its upper part close to the Ito cell, while sparse small granular and agranular vesicles (about $51 \mathrm{~nm}$ in diameter) tend to cluster in the bottom vacuolar part facing the Disse's space. Glycogen $\beta$-particles are scattered throughout the axoplasm.

The second extraordinarily large varicosity $(1.8 \mu \mathrm{m}$ in diameter $)$ in which abundant small mitochondria (about twenty) are filling the axoplasm was observed in a corresponding indentation on the perisinusoidal surface of the hepatocyte (Fig. 24). The right flat surface apposes across a nearly $25 \mathrm{~nm}$ wide cleft to the surface of the cytoplasmic segment probably of an Ito cell in the Disse's space. A small number of small granular as well as agranular vesicles (about $50 \mathrm{~nm}$ in diameter) and a few large densecored ones ( $90 \mathrm{~nm}$ in diameter) are gathered toward this surface making a loose cluster. 


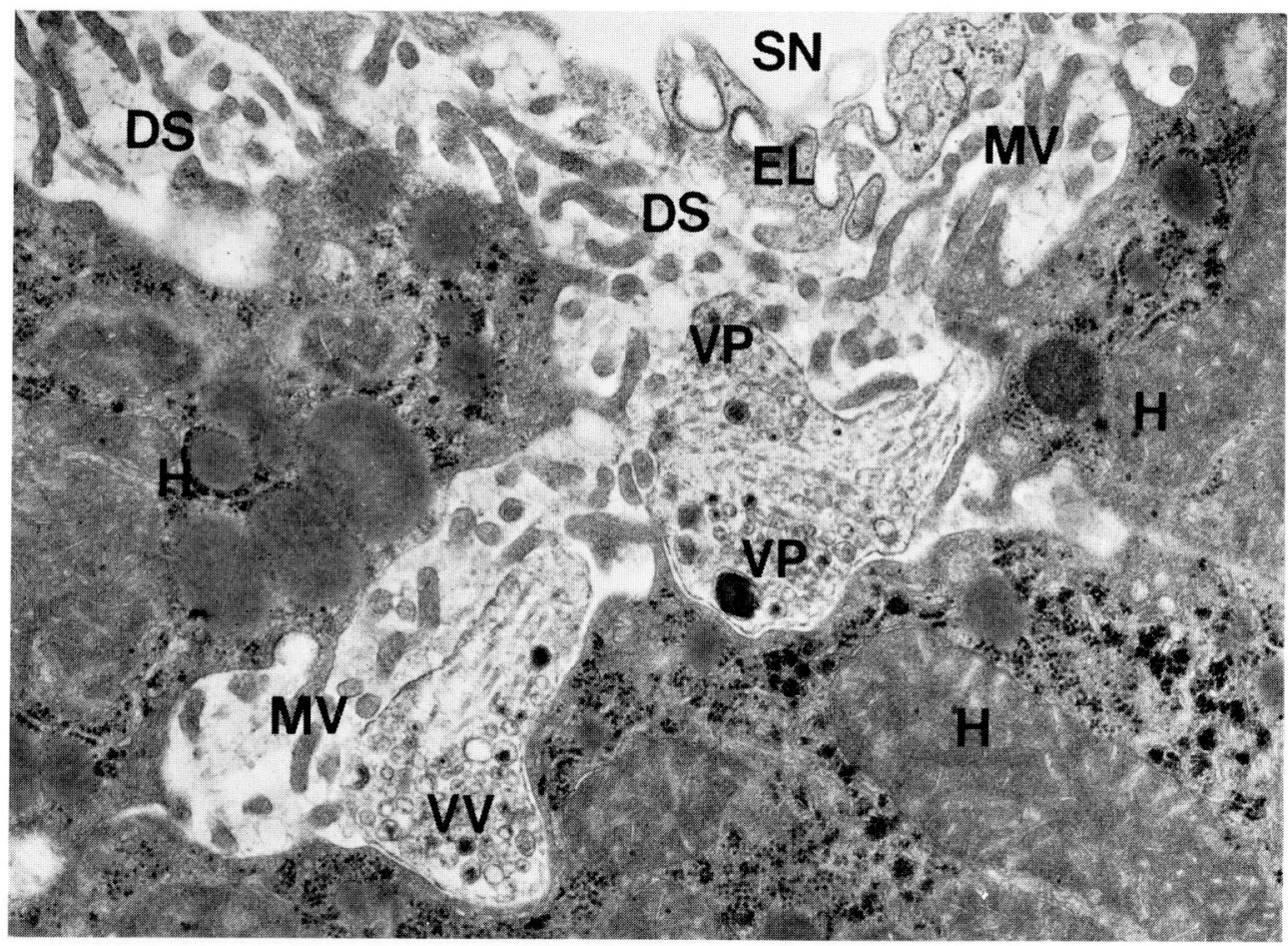

Fig. 15. Two vesiculate varicosities $(V V)$ are juxtaposed on the perisinusoidal surface of a hepatocyte $(H)$. The bottom varicosity makes a synaptic contact with the hepatocyte, and small granular, agranular and large granular vesicles are concentrated on this side, while the upper varicosity sends two protrusions (VP) of similar adrenergic nature, one making synaptic contact with the hepatocyte and the other extending into the Disse's space ( $D S$ ) to terminate freely at a place far away from the endothelial lining ( $E L$ ) of the sinusoid (SN). $M V$ microvilli. $\times 25,000$

Besides synaptic vesicles, small dense bodies and glycogen $\beta$-particles are scattered at random places in this varicosity. The above two large varicosities filled with small mitochondria may be traced to the mitochondria-packed large axon profiles found in the cross section of a nerve of the portal tract illustrated in Figure 7.

An unique, possible axon varicosity (1.4 $\mu \mathrm{m}$ in diameter) was observed fitting to an indentation induced on the surface of a hepatocyte facing the perisinusoidal space intervening between the sinusoidal endothelial perikaryon and the hepatocyte (Fig. 25). The axoplasm did not show any ordinary small and large vesicles, but rather smoothsurfaced straight or curved tubules, showing spindle, dumbell or club-shaped profiles, densely filling the axoplasm. Some of them are empty and lucid, whereas about one half of them are filled with electron dense powder-like material of variable electron densities. Between the limiting membrane and the electron dense core, an electron lucent halo is often observed. In this section shown in Figure 25, an elongate mitochondrion in the peripheral zone and many microtubules as well as electron dense glycogen $\beta$-particles are demonstrated. The nature of this curious varicosity encountered only once during the present study is unknown. 


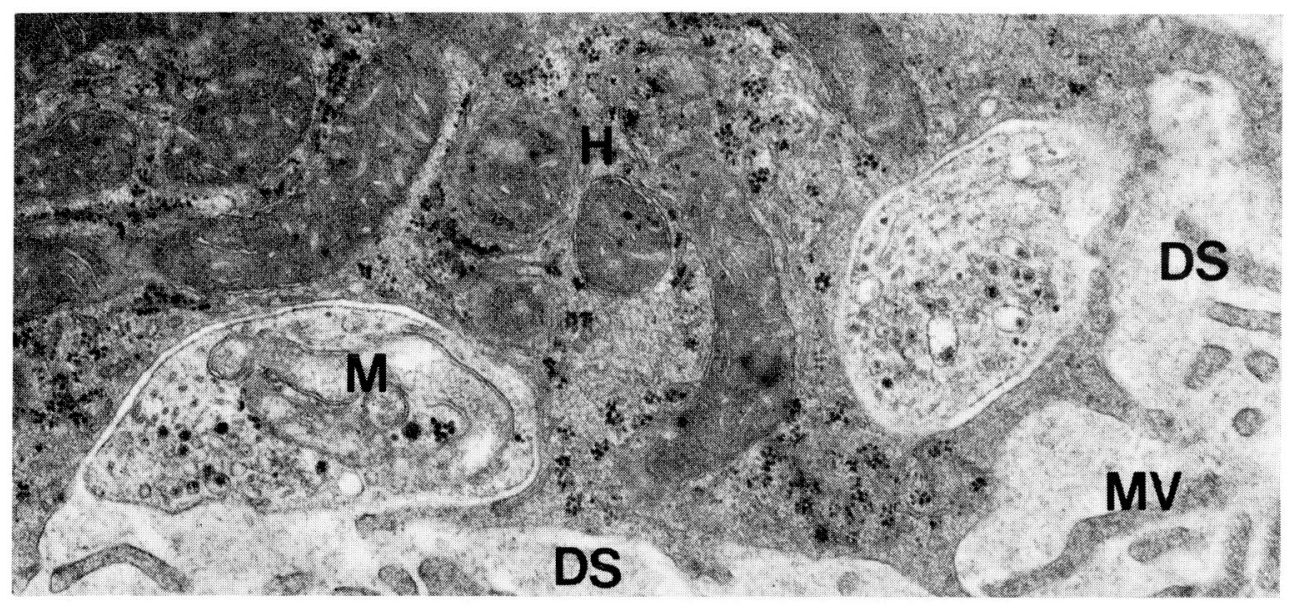

Fig. 16. Two vesiculate varicosities on the perisinusoidal surface of a hepatocyte $(H)$, embraced in its deep indentations and making a close synaptic contact with it. In the varicosity on the left side, however, synaptic vesicles of the adrenergic composition are concentrated toward the plasma membrane facing the Disse's space ( $D S$ ), suggesting the release of the transmitter substance into the latter. The opposite part facing the hepatocyte is occupied by mitochondria $(M) . \quad M V$ microvilli. $\times 25,000$

\section{DISCUSSION}

The cholinergic nerve fibers distributed in the hepatic tissue are thought to be derived from the postganglionic fibers of parasympathetic neurons located near the hepatic porta and in the portal space (tract) (SutherLand, 1964; Reilly et al., 1978). The adrenergic fibers supplying the hepatic tissue are believed to be postganglionic fibers of the celiac ganglion (McCuskey et al., 1979). However, the question concerning the nature of the autonomic axons found in the hepatic parenchyme, i.e., whether adrenergic or cholinergic or both remains controversial.

The previous studies have revealed, many unmyelinated nerves running in the portal tract along the interlobular arteries, veins and biliary ductules (portal triads) (SuTHERLAND, 1964; UngVáry and Donáth, 1969; Anufriew et al., 1973; SkaAring and Bierring, 1976; Forssmann and Ito, 1977; Reilly et al., 1978; McCuskey,

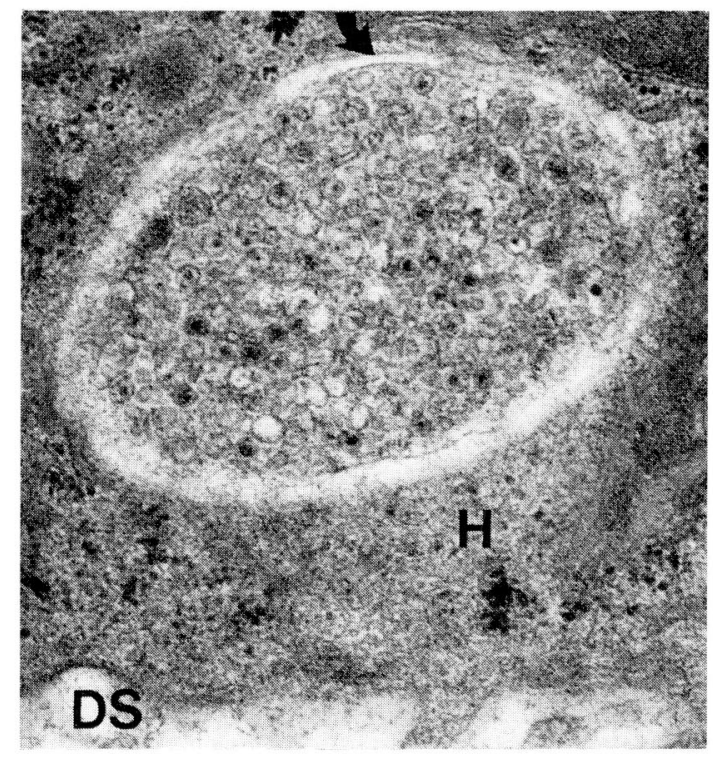

Fig. 17. Intrahepatocytic vesiculate varicosity making a synaptic contact with the hepatocyte $(H)$ across a circular synaptic cleft about $25 \mathrm{~nm}$ in width (arrow). This varicosity is packed with abundant small granular and agranular vesicles. Among the agranular vesicles flat ones are mingled. Large densecored vesicles are inconspicuous, and no mitochondria are seen in this section plane. DS Disse's space. $\times 40,000$ 


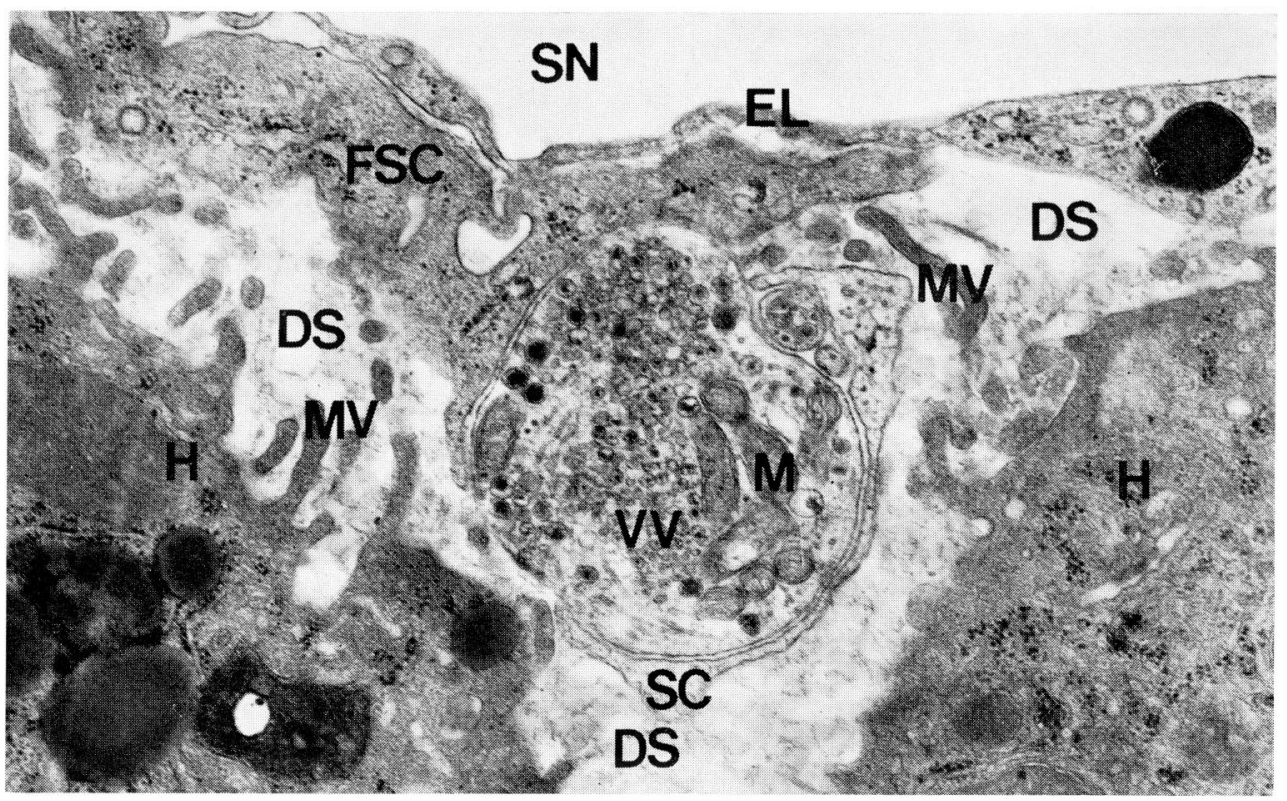

Fig. 18. Vesiculate varicosity $(V V)$ containing synaptic vesicles of the adrenergic composition and a cluster of many small mitochondria $(M)$ is eccentrically found in the right area of the axoplasm. The bottom right surface facing the Disse's space ( $D S$ ) is wrapped in Schwann cytoplasm (SC), but the upper left surface makes a synaptic contact with a part of an Ito cell (FSC), and the synaptic vesicles tend to concentrate toward this surface. EL endothelial lining, $H$ hepatocyte, $M V$ microvilli, $S N$ sinusoid. $\quad \times 25,000$

1979), but the electron microscopic fine structures of individual axons composing these nerves have mostly been overlooked.

In the present study on the guinea pig liver, fine structures of nerves running through the portal tract have been investigated. The results have elucidated that the thinner nerves were already composed of a variable number of varicose axons as is generally the case in the peripheral autonomic nerves. The vesiculate varicosities had naked surfaces toward the connective tissue, devoid of the Schwann sheath and covered only with a basal lamina surrounding the entire surface of the nerve. In guinea pig livers, all vesiculate varicosities found in the portal space contained small granular and agranular vesicles (20-60 $\mathrm{nm}$ in diameter) besides a few large dense-cored vesicles $(70-90 \mathrm{~nm}$ in diameter), they were thus all taken to be adrenergic. In the vesiculate varicosities, the small and large vesicles tended to be gathered towards their naked surface facing the portal tract and some of them appeared to rest on the plasma membrane, suggesting the emiocytotic release of the transmitter substance there. As measured in the longitudinal section of the small nerves composed of a few varicose axons, their naked surface totaled a considerably large area; in other words, the transmitter-releasing surface of the vesiculate varicosities in the portal tract seemed to attain a large extent. In the portal space of the guinea pig liver, no close synaptic connections have ever been observed between the vesiculate varicosities and abutting other cell types, and the transmitter substance was presumed to be released into the connective tissue space to arrive by diffusion to the elements of the portal triad, i.e., fibroblasts, mast cells, hepatocytes of the limiting plate (portal lamina) etc. regulating their function (synapse per distance, Jabonero, 1959; diffusion innervation, YAMAuCHI, 


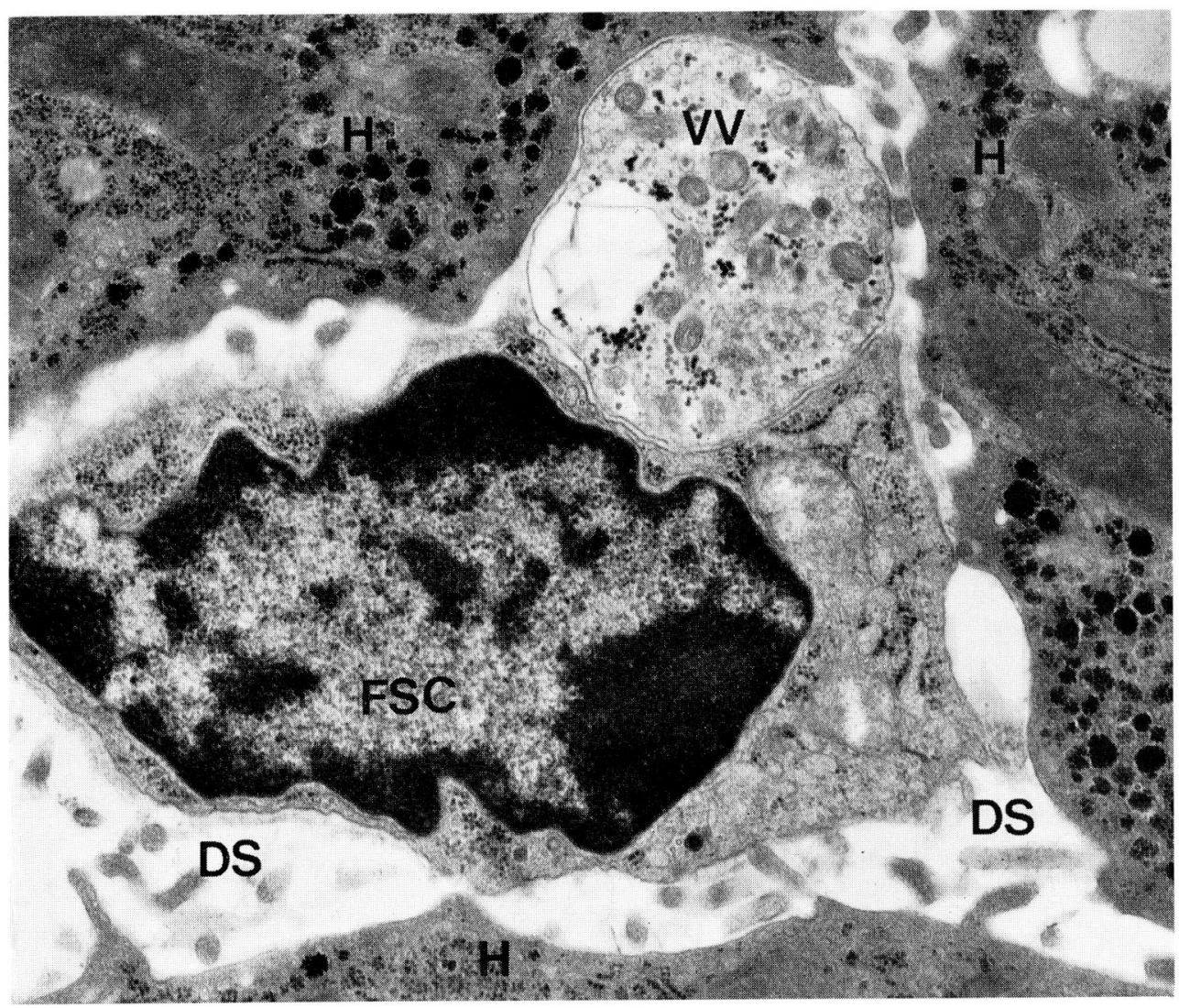

Fig. 19. A large mitochondria-rich varicosity ( $V V)$, possibly representing a sensory terminal in the Disse's space (DS) and making contact with an empty Ito cell (FSC) on one hand and a hepatocyte $(H)$ on the other. It is characterized by large size, numerous small round mitochondria scattered in the axoplasm, many glycogen particles and a small number of agranular and granular vesicles. $\times 25,000$

1964; en passage release of transmitter from varicosities, Bunnstock and Iwayama, 1971) (see also Yамамото, 1977). The present electron microscopic study on the guinea pig liver for the first time gave the morphological data supporting the secretion of neurotransmitter substance from the vesiculate varicosities of the portal canal nerves. Thus, the present study has given electron microscope evidence that the blood vessels distributed in the portal canal may receive adrenergic control as claimed by NoBIN et al. (1978).

In their review on the hepatic innervation, McCuskey et al. (1979) described that nothing is known about hepatic sensory nerves. Sawchenko and Friedman (1979) reported in their review on the liver's sensory function that several lines of evidence suggested that the afferent innervation of the liver might be substantial, although few anatomical studies directly addressed the question concerning an hepatic sensory supply. They further noticed that the anatomical evidence of afferent nerve endings in the liver must largely rest on morphological similarity between nerve endings in the liver and known sensory receptors. Many electron microscopic reports have been published concerning the free and encapsulated sensory receptors in the skin (PEASE 


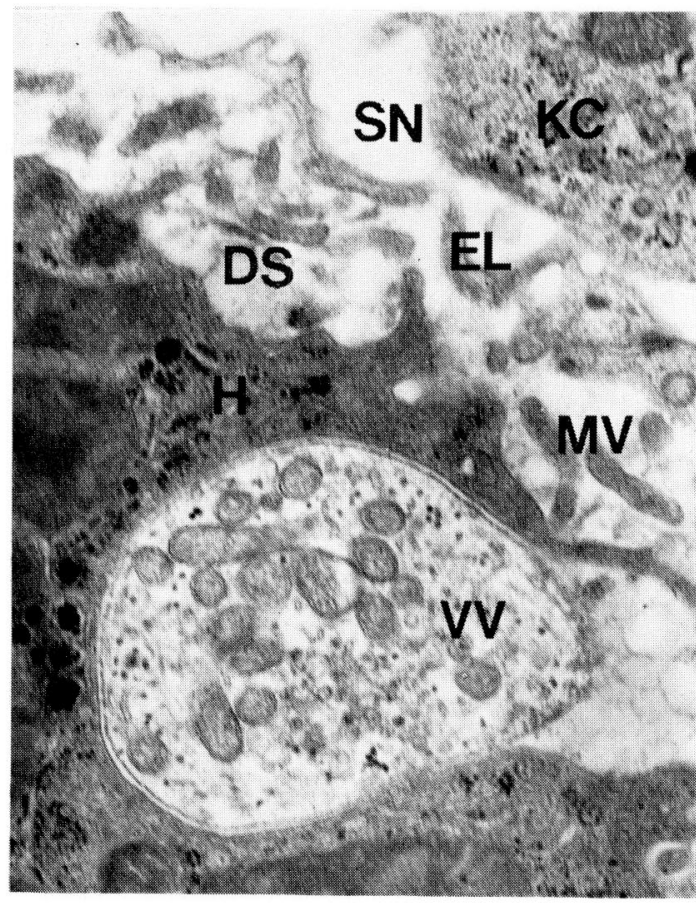

Fig. 20. A large mitochondria-rich varicosity ( $V V)$, presumably representing a sensory terminal in the Disse's space (DS) and making close contact with a hepatocyte $(H)$ embraced deeply in it. It shows features identical with those in the large sensory terminal in Figure 19. EL endothelial lining, $K C$ Kupffer cell, $M V$ microvilli, $S N$ sinusoid. $\quad \times 26,000$ and Quilliam, 1957; Cauna and Ross, 1960; Yамамото, 1966; Cauna, 1970; Smith jr., 1970; Suzuki and Kurosumi, 1972; Spencer and Schaumberg, 1973, etc.) and in the mucosa (Вöck, 1970; Martinez and Pekarthy 1974; Hung, 1976; Watanabe, 1982; Watanabe and Yamada, 1983). According to these reports, free or endorgan-ensheathed afferent axons were loaded with abundant small mitochondria in addition to small vesicles of variable electron density and occasional glycogen particles.

In their electron microscopic studies on the smooth muscle of vas deferens and intestine, Burnstock and Iway ama (1971) and Merrillees (1968) regarded some axon profiles as sensory, as they contained a large number of small mitochondria with two cristae, and a few, if any, agranular vesicles. ChiBa and Yamauchi (1970) studied electron microscopically axons distributing in the human ventricular and atrial myocardium and revealed a few per-cent of axon profiles to be remarkably large in diameter being packed with abundant mitochondria along with some vesicles, glycogen rosettes and lysosomes. They regarded these large mitochondria-rich axons as terminal portions of the cardiac afferents.

In the nervous plexus in the guinea pig ileum and in bat and mouse small intestine Gabella (1972) and Yамамото (1977, 1980) demonstrated nerve processes as well as terminals or varicosities filled with small mitochondria; ҮАмамото (1980), referring to the axons loaded with numerous mitochondria typical of sensory receptors, regarded them as possible sensory endings.

So far as the present author knows, this type of presumed sensory axons has not yet been reported in mammalian livers. In the present study, however, a cross section of a relatively large unmyelinated nerve which was mainly composed of several extraordinarily large nerve fibers averaging $2.5 \mu \mathrm{m}$ in diameter on an average filled with accumulation of numerous small mitochondria has been revealed in the portal tract of the guinea pig liver, being wrapped almost uninterruptedly in the Schwann sheath accompanied by basal lamina. A few small ordinary autonomic axon profiles averaging $780 \mathrm{~nm}$ in diameter were contained in the peripheral part of this nerve. On the basis of these findings, it can be concluded that they might be sensory nerve fibers entering the hepatic parenchyme through the porta hepatis and the subsequent portal canal. As shown by Iwayama et al. (1970), Burnstock and Iwayama (1971) and 


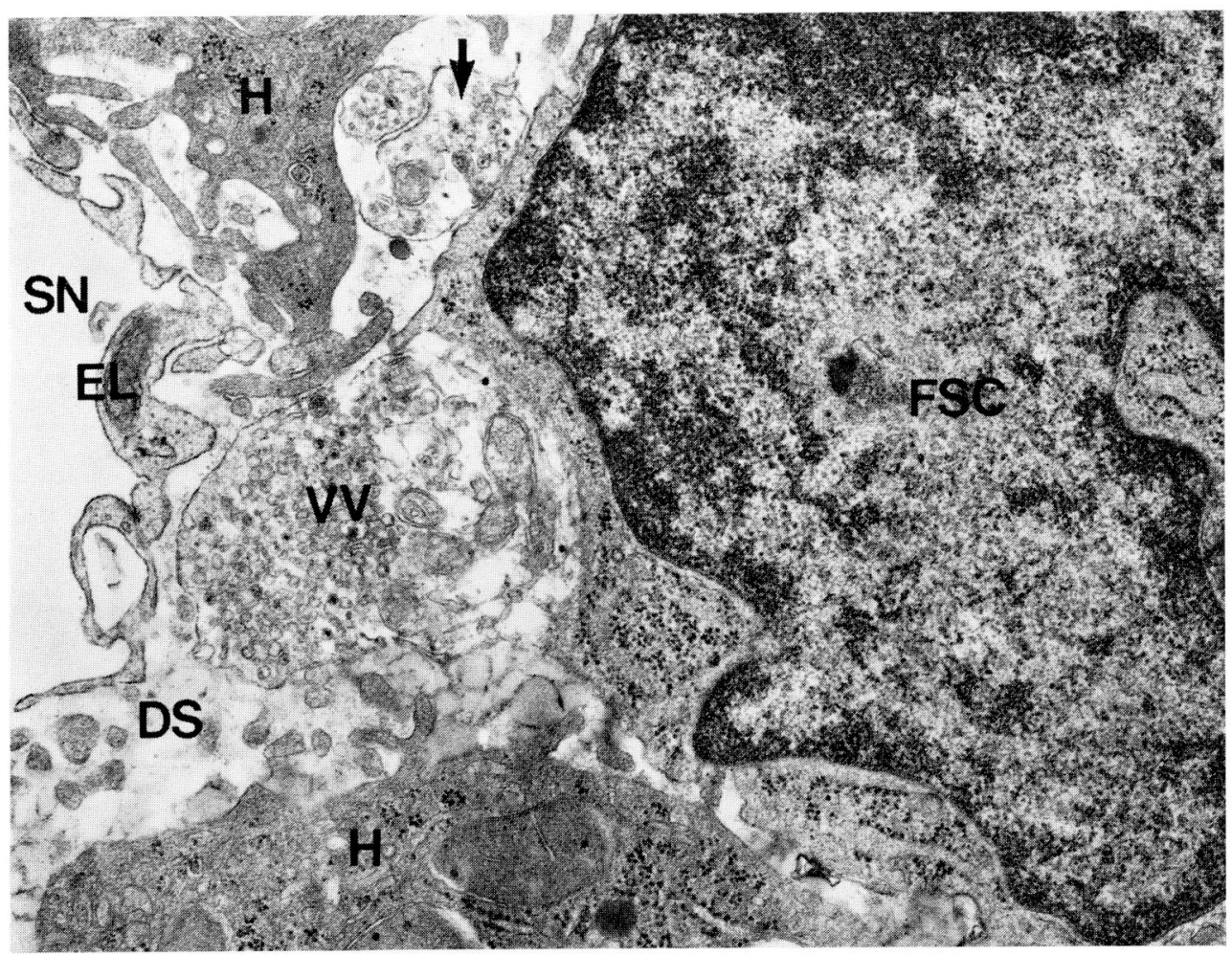

Fig. 21. A vesiculate varicosity ( $V V)$ of an ordinary size in the Disse's space (DS). Its vacuolar outer pole, containing but small mitochodria closely fits, with its convex surface, to a concavity on an Ito cell (FSC); the opposite perisinusoidal pole is densely packed with small agranular and granular veiscles, some of which anchor on the plasma membrane. This membrane faces the endothelial lining (EL) of the sinusoid (SN) across a $60-120 \mathrm{~nm}$ wide cleft, assumably forming a "synapse per distance" between them. A small adrenergic terminal (arrow) facing an Ito cell is detectable on its upper left surface. $H$ hepatocyte. $\times 26,000$

BuRnstock (1972), they might possibly be traced by serial sectioning back to myelinated axons.

In the Disse's space and interhepatocytic space, thin nerve branches coming from the portal space ran closely along the perisinusoidal surface of the hepatocytes as already shown by ITo and Shibasaki (1968) in the human liver, either partly enclosed by Schwann cytoplasm or completely devoid of it. They were composed of axons with periodic varicosities. In the guinea pig liver as in the human liver, the nucleated portion of the Schwann cell was also extremely rare in the Disse's space (Ito and SHibasaki, 1968). In the Disse's space both the Schwann cytoplasm and the axon bundle including vesiculate varicosities were usually devoid of the basel lamina in contrast to those in the portal space, if they were located at a certain distance away from the latter.

In the guinea pig, the most numerous axon terminals or vesiculate varicosities were encountered either in synaptic contact with the concavities on the perisinusoidal surface of the hepatocytes, embraced in their indentations or occasionally embedded within the cytoplasm of the hepatocyte surrounded by a circular synaptic cleft (YAMADA, 1965). 


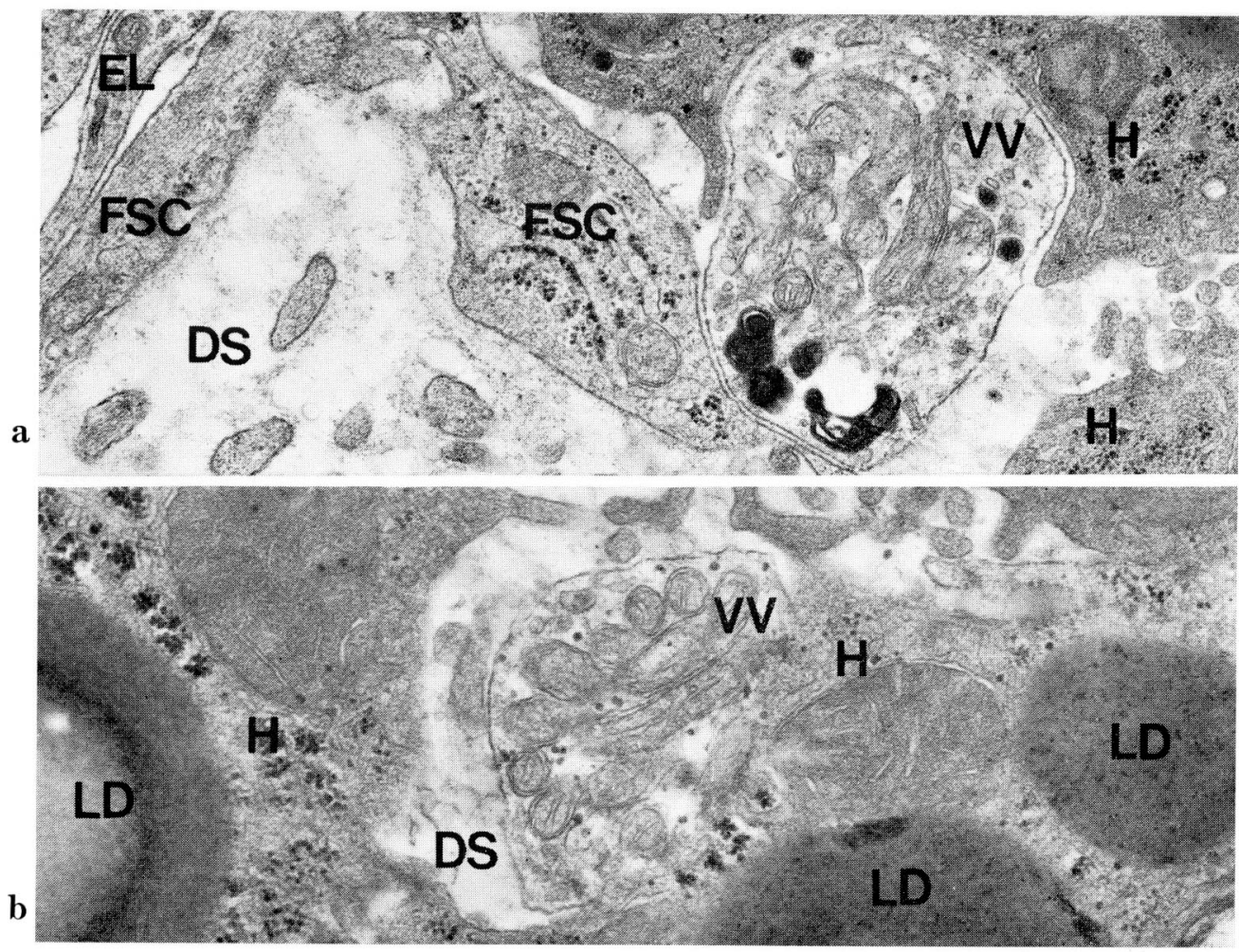

Fig. 22. Small vesiculate varicosities $(V V)$ in the Disse's space (DS) packed with small mitochondria in contrast to sparse synaptic vesicles. These varicosity profiles may have been caused by sectioning the ordinary vesiculate varicosities through the part containing many mitochondria. a. The varicosity makes a contact with a hepatocyte $(H)$ on one side and on the other with an Ito cell $(F S C)$. EL endothelial lining of the sinusoid. $\times 31,500 . \quad$ b. A varicosity and an adjacent hepatocyte $(H)$ probably making a synaptic contact, although synaptic membranes are obscure. $L D$ lipid droplets of hepatocytes. $\times 31,200$

In the Disse's space, two neighboring vesiculate varicosities of an axon occasionally made synaptic contacts simultaneously with a hepatocyte and an Ito cell. It was not rare to find of a hepatocyte in one section including not only one but also two vesiculate varicosities residing in its indentations on the perisinusoidal surface. These synaptic varicosities contained variable numbers of small agranular as well as granular vesicles $(20-60 \mathrm{~nm}$ in diameter) and sparse large dense-cored vesicles $(70-90 \mathrm{~nm})$ in addition to a small number of small mitochondria and occasional glycogen $\beta$-particles. In the majority of the vesiculate terminals to the hepatocytes, the small synaptic vesicles were accumulated close to the hepatocyte. Occasionally, however, small synaptic vesicles were accumulated on the opposite side of the axoplasm, separated from the Disse's space merely by the naked plasma membrane. In such a case the release of the transmitter substance into the Disse's space was expected. Some of the vesiculate axon varicosities running in the Disse's space, made synaptic contact neither with the hepatocyte nor with the Ito cell, but terminated freely in the Disse's space (Fig. 13). Only rarely did an axon varicosity divide into two vesiculate protrusions, one extending into an indentation on the perisinusoidal surface of a hepatocyte to make synaptic contact with it, and the other into the Disse's space to terminate freely and possibly 


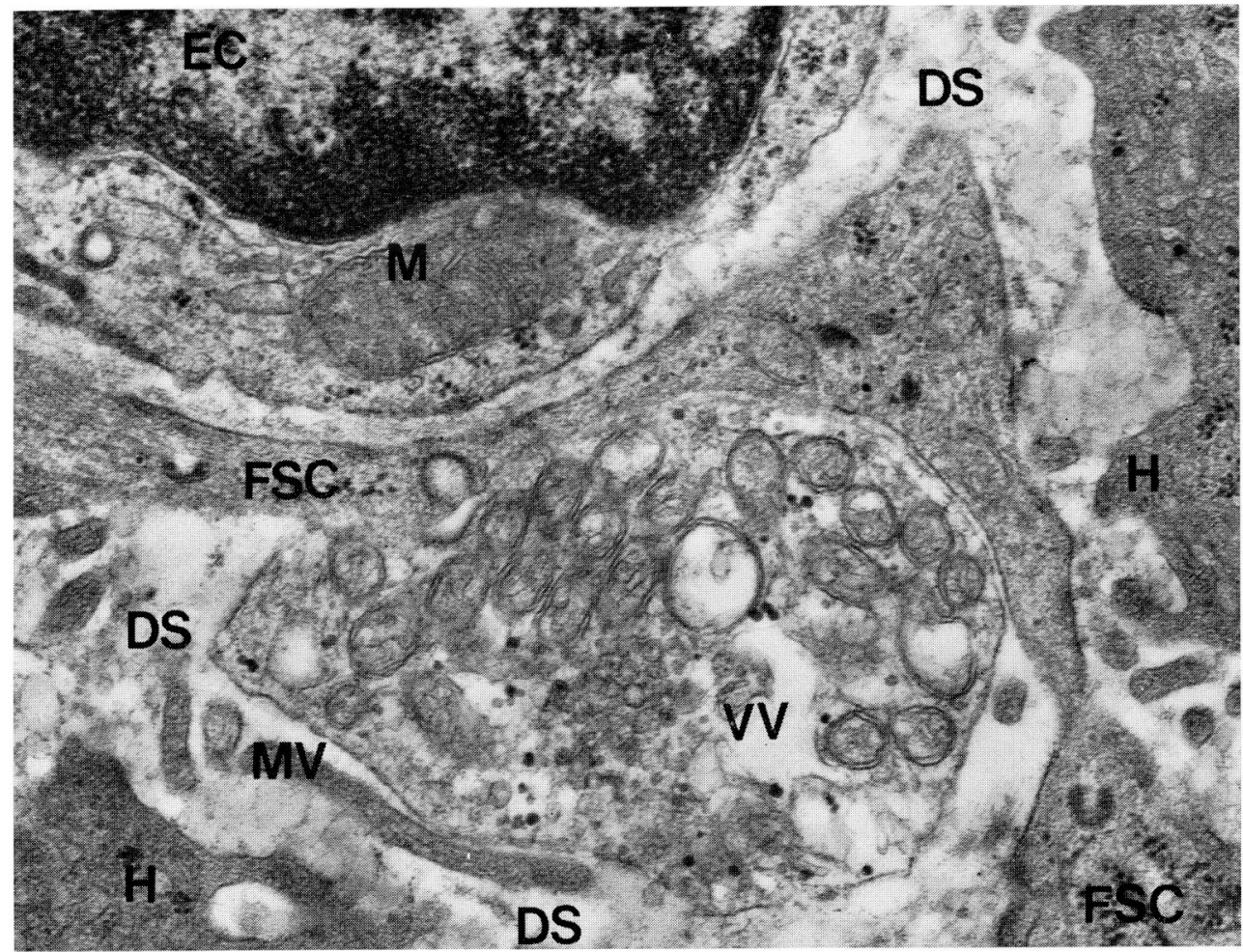

Fig. 23. Large vesiculate varicosity (VV) in the Disse's space (DS) containing abundant small mitochondria, densely clustered in the upper part, which makes close contact with an Ito cell (FSC), elongated along the perikaryon of the endothelial cell (EC). This presumable sensory terminal contains a few small agranular and granular vesicles in the bottom part facing the Disse's space, and moreover possesses glycogen particles. $H$ hepatocyte, $M$ large mitochondrion in the endothelial perikaryon, $M V$ microvilli. $\quad \times 39,000$

release a transmitter substance into it. The sum of the transmitter substances to be released into the Disse's space, as well as into the portal space, can be presumed to be a considerable amount. As for the synaptic connections between hepatocytes and the autonomic vesiculate terminals, many authors, including YAMADA (1965) and ITO and SHIBASAKI (1968), have reported them in various vertebrates (Forssmann and ITo, 1977; Uno, 1977; Nobin et al., 1978; Reilly et al., 1978; Tsuneki and Ichihara, 1981 etc.). SATLER et al. (1974), however, could not reveal any direct connections between nerve terminals and hepatocytes in the rat, thus assuming only diffusion innervation to hepatocytes (synapse per distance). Although Forssmann and ITo (1977) proposed the hypothesis that there might be a inverse relation between the number of synaptic terminals to hepatocytes and the number of gap junctions in hepatocytes, McCuskey et al. (1979) doubted the actual propagation of nervous influence from the portal lamina (limiting plate) to the whole hepatic lobule by means of gap junctions.

The present electron microscope study has evidenced that autonomic nerves distributed in the potal tract, Disse's space and hepatic parenchyme of the guinea pig liver were entirely adrenergic, because all axon terminals contained noradrenalinstoring small granular vesicles.

As to the nature of of autonomic nerves distributed in the liver, especially its 


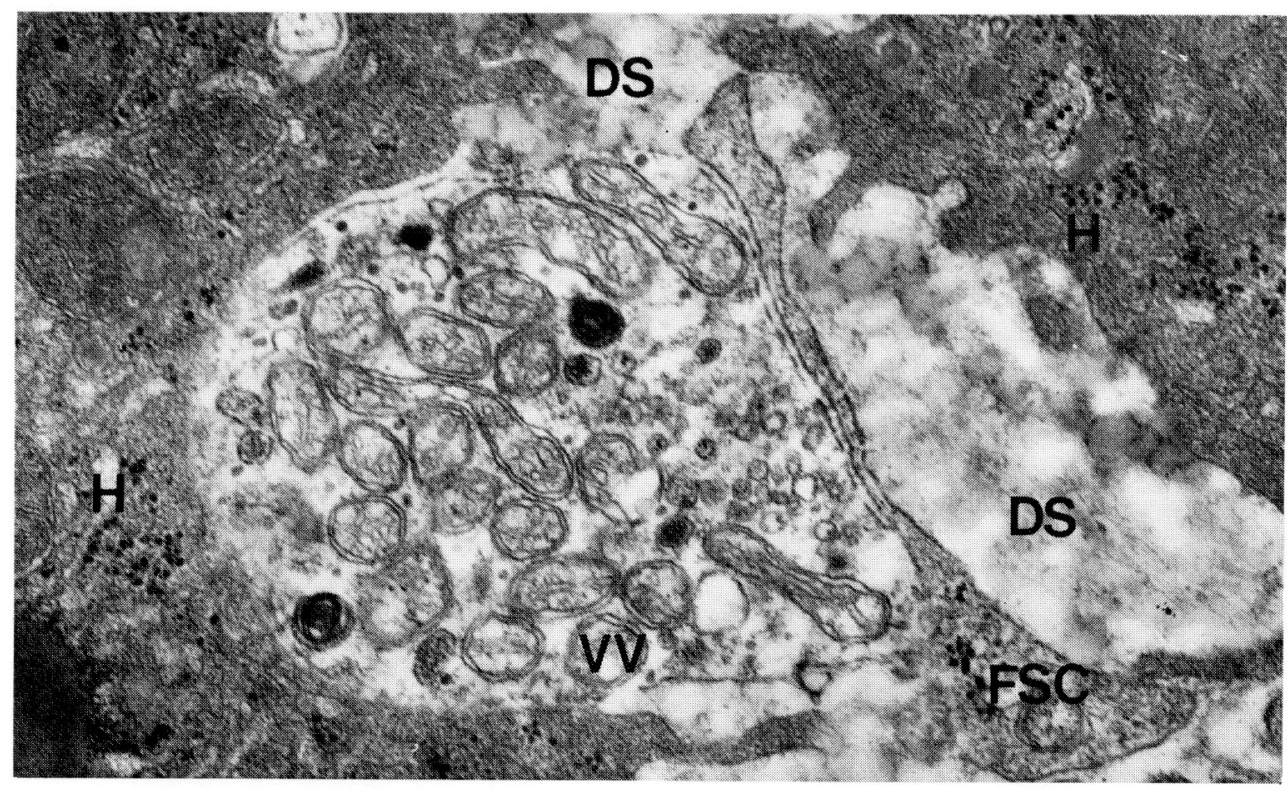

Fig. 24. Large vesiculate varicosity ( $V V)$ in the Disse's space (DS) containing abundant small mitochondria closely packed in the left part of the axoplasm. This presumed sensory terminal fits an indentation of the hepatocyte $(H)$ with its convex left surface. Its right flat surface makes contact with an Ito cell (FSC). Sparse small granular and agranular vesicles are concentrated close to the Ito cell. In addition, a few large dense-cored vesicles, lysosomes and glycogen particles are scattered. $\times 39,000$

parenchyme, there have been divergencies of opinions, according to SuTHERLAND (1964), nerves supplying the parenchyme and blood vessels in the portal space of guinea pig and several mammals were cholinergic, while according to AnUfRIEw et al. (1973) they were adrenergic in the guinea pig and several mammals, both in their parenchyme and Glisson's sheath, including blood vessels. A study by SkAARING and BiERring (1976) on the rat liver proved that the blood vessels in Glisson's sheath were supplied by adrenergic nerves while hepatic parenchyme by cholinergic ones. Forssmann and Ito (1977) concluded in their studies in the tupaia (tree shrew) that both the Glisson's sheath and hepatic parenchyme (lobule) received only adrenergic nerve supply as claimed by Yamada (1965) in the mouse and by Ito and Shibasaki (1968) in the human. These findings, identical with ours, were confirmed by NoBIN et al. (1978) in their studies on human and monkey livers. They denied the major cholinergic innervation in the primate livers, but in functional respects such as in glucose metabolism, they gave the evidence of supply by both nerves. The studies by Uno (1977) on the macaque liver revealed both adrenergic and cholinergic nerve terminals in the hepatic parenchyme. ReILly et al. (1978) gained similar findings in the rat liver innervation.

Only a few papers are available concerning the electron microscope studies on the nerve supply of the three types of sinusoidal cells, i.e., Ito's fat-storing cell, the sinusoidal endothelial cell and the Kupffer cell. Adrenergic innervation of the Ito cell was reported for the first time by ITo and Shibasaki (1968) and later again by Ito (1973) in the human liver. Recently, TsuneKI and ICHIHARA (1981) have demonstrated nerve terminals (possibly adrenergic) to the Ito cells in the rabbit and pigeon. In the present study on guinea pig livers, adrenergic terminals to the Ito cell were not rare. The fine 


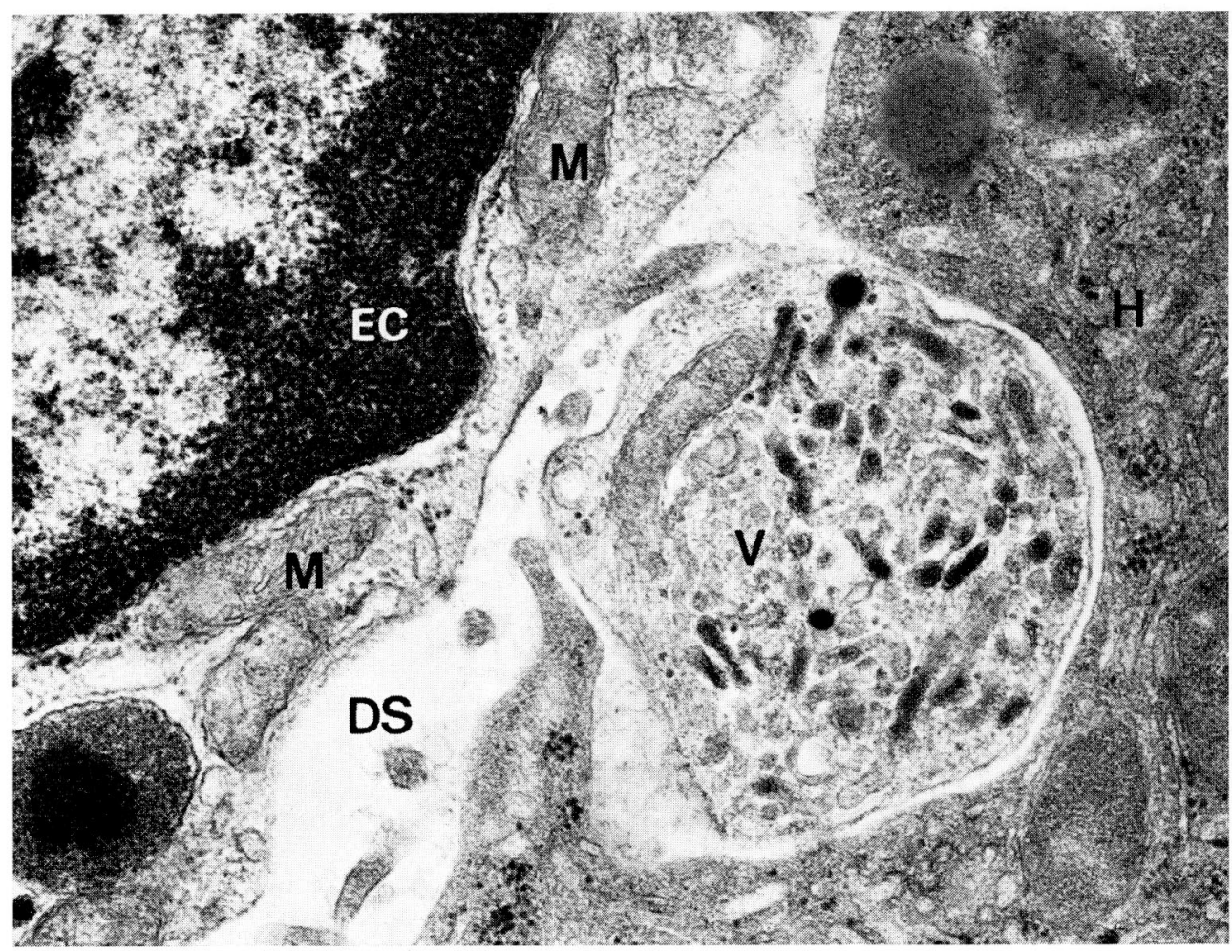

Fig. 25. A peculiar axon varicosity $(V)$ found only once in the present study. It is embraced in an indentation on the perisinusoidal surface of a hepatocyte $(H)$. It contains, instead of typical synaptic vesicles, smooth-surfaced tubules showing spindle-shaped, dumbell-shaped and clubshaped profiles, nearly half of which contain an electron dense powder-like material; an electron lucent halo is often observed between the limiting membrane and the electron dense core. In addition, microtubules, glycogen particles and an elongate small mitochondrion are seen. $D S$ Disse's space, $E C$ sinusoidal endothelial perikaryon, $M$ large endothelial mitochondria. $\times 43,000$

structures of these adrenergic terminals and their synaptic relations were identical with those of the synapses to hepatocytes.

Morphological features of a direct nerve supply to the sinusoidal endothelium and Kupffer cell have not yet been clarified. In their study on the tree shrew liver, FoRSSMANN and ITo (1977) briefly reported that some adrenergic nerve fibers were observed in close association with the Kupffer and the endothelial cell. In the present study, a number of synaptic connections between the sinusoidal endothelium and adrenergic terminal were observed, but synaptic clefts were remarkably wider than in the cases of ordinary synaptic contacts; they were reasonably referred to as the "synapses per distance." In the present study, only two cases of the innervation of the Kupffer cell were observed. In one case, a Kupffer cell came in contact with a naked axon which was embraced between Kupffer cell processes protruding into the sinusoidal lumen. In the other case, a Kupffer cell protruded a clubbed process into a nerve bundle in the Disse's space, and made a possible adrenergic synaptic contact with an axon varicosity across a synaptic cleft about $60 \mathrm{~nm}$ in width. As to the strong hemodynamic responses of the sinusoidal endothelial lining to adrenergic and cholinergic transmitter 
substances, McCuskey et al. (1979) made a detailed review, especially pointing out that histamine and serotonin released by cholinergic mechanism from mast cells of the portal tract appeared to alter the sieve plate in the sinusoidal lining, thus affecting the permeability of the sinusoidal wall. The question as to what effects these substances and neurotransmitters might exert on the Kupffer cell functions has remains unanswered. The present study also assumed the influence of the adrenergic transmitter substance which arrived at the sinusoidal endothelium and the Kupffer cell through synaptic contacts or through diffusion or by flow into the sinusoid via sieve plates.

If histamine and serotonin were released only by the cholinergic mechanism as proposed by McCuskey et al. (1979), their effects on the endothelial lining of the guinea pig liver would not be presumed, since in guinea pig liver, cholinergic terminals have not been detected.

Numerous ordinary vesiculate varicosities or terminals $(1.2 \mu \mathrm{m}$ in diameter on an average) found in the parenchyme of the guinea pig liver contained adrenergic vesicles accompanied by glycogen $\beta$-particles, small mitochonodria with sparse cristae and occasional lysosomes. Density increase and thickening of the synaptic membranes were not recognized, as several authors noticed (Nobin et al., 1978; SAWCHENKo and FriEdman, 1979, etc.).

The present study has revealed in the guinea pig liver a number of extraordinarily large terminals $(1.7 \mu \mathrm{m}$ in diameter on an average) which contained abundant small mitochondria with sparse cristae, accompanied by only a few small agranular, granular vesicles (about $52 \mathrm{~nm}$ in diameter on an average) and scanty large dense-cored vesicles (about $90 \mathrm{~nm}$ in diameter on an average). These extraordinarily large terminals could be classified into three types: Type 1 terminals, observed only once, were characterized by their giant size (about $200 \mathrm{~nm}$ in diameter), irregular shape and abundant small mitochondria. Among the mitochondria, many glycogen particles were scattered. Only this type of varicosity was ensheathed in Schwann cytoplasm and made no synaptic connection with hepatocyte or Ito cell, so that it might be presumed to be a presynaptic portion of a large sensory axon passing through the Disse's space. Type 2 terminals characterized by the most abundant small mitochondria (over twenty) which made a dense accumulation. Glycogen particles were also intermingled. The varicosity was closely juxtaposed with the Ito cell and/or hepatocyte across a cleft about $20 \mathrm{~nm}$ in width. Type 3 varicosities, were characterized by abundant small round mitochondria with sparse cristae which were loosely scattered in the vacuolar axoplasm, and by a relatively large amount of glycogen particles. It made a close contact with the Ito cell and/or the hepatocyte over a cleft about $20 \mathrm{~nm}$ in width. These types 1,2 and 3 could be considered as sensory terminals of afferent axons. They were probably derived from large sensory axons packed with abundant small mitochondria detected in the portal space of the guinea pig liver, and they were all clearly distinguished from the ordinary adrenergic terminals by thier large sizes, abundance of small mitochondria and contrarily minute amounts of small vesicles. These characteristics also agreed with those of the free sensory axon terminals and those in encapsulated sensory receptors in the skin and mucosa described by the many authors cited adove. The majority of these authors detected a variable number of vesicles in the sensory terminals along with abundant mitochondria; Yамамото (1966), SuzuKi and Kurosumi (1972), W ATANABE (1982), W ATANABE and YamadA (1983) etc. found small clear vesicles, CAUNA and Ross (1960) small dense vesicles and Hung (1976) large dense-cored vesicles. Only Spencer and Schaumberg (1973) observed, in agreement with the present author, clear and dense-cored vesicles of synaptic vesicle size. Martinez and Pekarthy (1974) 
described in their paper numerous (clear) microvesicles only, but in their electron micrograph (Fig. 2) besides clear vesicles, some small granular (dense-cored) ones were also detectable. ChiBa and Yamauchi (1970) illustrated in the mitochondria-rich large axon terminal portions of the cardiac afferents some small agranular vesicles and large granular ones. As to the functional significance, SPENCER and SCHAUMBERG suggested that the clear vesicles in sensory terminals contained a substance which might be released during distortion of the axon processes and then be able to effect the ionic conductance of the axolemma. They described, however, nothing about the dense-cored vesicles which are also contained in the terminals, although CAUNA and Ross (1960) assumed that the small dense vesicles must be synaptic vesicles. The present study could not solve questions concerning either the functional significance of the small vesicles or especially concerning the chemical nature of the dense cores of the small and large granular vesicles. In the cytoplasm of the hepatocyte or of the Ito cell synaptically connected with the presumed sensory terminal over a cleft about $20 \mathrm{~nm}$ in width there have been found no vesicles or granules have been found in the areas near the cleft.

As for the signficance of the mitochondria, CAUNA and Ross (1960) assumed that the accumulation of mitochondria in the endings might reflect an extremely high rate of metabolism, possibly involved in the propagation of the impulse. Suzuki and KuroSUMI (1970) proposed a possibility that they may transform the mechanical or chemical stimuli into nerve excitation. The present author, confirming the occurrence of abundant mitochondria in the presumed sensory axons and terminals in the guinea pig liver, assumes that they might be responsible for the extensive energy production necessory for the propagation of the impulse at the peculiar speed toward the center contrary to that of the normal and retrograde axon flows. Since ITo and Shibasaki (1968) revealed a solitary cilium of human Ito cells protruded into the Disse's space, which they presumed to be a sensory cilium or chemoreceptor, this metaplasmic structure developed from the distal centriole of the diplosome has been confirmed by many workers in a variety of vertebrate species (WAKE, 1971; YАмАмото, 1975; YАMAмото and EnZAN, 1975; TANuma and Ito, 1978, 1980; TANuma et al., 1981, 1983; Ohata et al., 1982) and has been believed to be a possible sensory apparatus of this cell. It is noteworthy that synaptic connections between the Ito cell and presumed sensory terminal have frequently been observed in the guinea pig liver, since a hypothesis might reasonably be proposed that the Ito cell may be excited by chemical or physical stimuli received by the solitary cilium from the content of the Disse's space. This excitation is possibly conducted across the synaptic cleft to the terminal to be further propagated toward the center due to the energy supply by numerous mitochondria and glycogen contained in the nerve.

The same may also be the case in the conduction of the excitation caused from the interior of the hepatocyte across the narrow cleft to the presumed sensory terminal to be further propagated toward the center through the afferent axon.

In both cases, however, difficulty might consist in the existence of a minute cleft about $20 \mathrm{~nm}$ in width between the juxtaposed plasma membranes of the effector cell and the receptive terminal instead of a connection by means of a gap junction. As proposed by SPENCER and SCHAUMBERG (1973), the present author conceives a possibility that the clear and granular vesicles commonly present in the sensory terminals, also detected in the guinea pig liver, might effect the ionic conductance of the axolemma to assume a role in the solution of this difficulty. Recently, Shibasaki (1982) has demonstrated, in the Disse's space of the human liver, a large varicosity containing abundant small round mitochondria with sparse cristae and a low number of small 
granular as well as agranular vesicles. It made close contact with both an Ito cell and a hepatocyte on the opposite sides. This large varicosity of SHibasaki seens identical with our type 2 or 3 presumed sensory varicosities in the guinea pig liver.

\section{REFERENCES}

Anufriew, B. T., Yu. K. Eletskii and N. A. Smitten: Histochemical investigation on the adrenergic innervation on the liver. Bull. exp. Biol. Med. 75: 584-586 (1973).

Böck, P.: Die Nerven der Papilla filiformis der Zunge vom Meerschweinchen. Arch. histol. jap. 32: 399-411 (1971).

Burnstock, G.: Purinergic nerves. Pharmacol. Rev. 24: 509-580 (1972).

Burnstock, G. and T. Iwayama : Fine-structural identification of autonomic nerves and their relation to smooth muscle. Progr. Brain Res. 34: 389-404 (1971).

Cauna, N.: The fine morphology of the sensory receptor organs in the auricle of the rat. J. comp. Neurol. 136: 81-98 (1972).

Cauna, N. and L. L. Ross: The fine structure of Meissner's touch corpuscle of human fingers. J. biophys. biochem. Cytol. 8: 467-482 (1960).

Chiba, T. and A. Yamauchi : On the fine structure of the nerve terminals in the human myocardium. Z. Zellforsch. 108: 324-338 (1970).

Forssmann, W. G. and S. Ito: Hepatocyte innervation in primates. J. Cell Biol. 74: 299-313 (1977).

Fujita, T. and S. Kobayashi : Proposal of a neurosecretory system in the pancreas. An electron microscope study in the dog. Arch. histol. jap. 42: 277-295 (1979).

Gabella, G.: Fine structure of the myentric plexus in the guinea-pig ileum. J. Anat. 111: 69-97 (1972).

Hung, K. S.: Fine structure of tracheo-bronchial epithelial nerves of the cat. Anat. Rec. 185: 85-92 (1976).

Ito, T.: Recent advances in the study on the fine structure of the hepatic sinusoidal wall. Gunma Rep. Med. Sci. 6: 119-163 (1973).

Ito, T. and S. Shibasaki : Electron microscopic study on the hepatic sinusoidal wall and the fatstoring cells in the normal human liver. Arch. histol. jap. 29: 134-192 (1968).

Iwayama, T., J. B. Furness and G. Burnstock: Dual adrenergic and cholinergic innervation of the cerebral arteries of the rat. An ultrastructural study. Circulation Res. 26: 635-646 (1970).

Jabonero, V.: Die plexiforme Synapse auf Distanz und die Bedeutung der sogenannten interkalären Zellen. Acta neuroveg. 19: 276-302 (1959).

Martinez, B., jr. and J. M. Pekarthy : Ultrastructure of encapsulated nerve endings in rat gingiva. Amer. J. Anat. 140: 135-138 (1974).

McCuskey, R. S., F. D. Reilly and P. A. McCuskey : Innervation of the liver as it relates to the sinusoid. Kupffer Cell Bull. 2: 4-7 (1979).

Merrilleess, N. C. R.: The nervous environment of individual smooth muscle cells of the guinea pig vas deferens. J. Cell Biol. 37: 794-817 (1968).

Nobin, A., H. G. Baumgarten, B. Falck, S. Ingemansson, E. Morghimzadeh and E. Rosengren : Organization of the sympathetic innervation in liver tissue from monkey and man. Cell Tiss. Res. 195: 371-380 (1978).

Ohata, M., Y. Tanuma and T. Ito: Electron microscopic study on avian livers with special remarks on the fine structure of sinusoidal cells. Okajimas Fol. anat. jap. 58: 325-368 (1982).

Pease, D. C. and T. A. Quilliam: Electron microscopy of the Pacinian corpuscle. J. biophys. biochem. Cytol. 3: 331-342 (1957).

Reilly, F. D., P. A. McCuskey and R. S. McCuskey : Intrahepatic distribution of nerves in the rat. Anat. Rec. 191: 55-68 (1978). 
Riegele, L.: Über das feinere Verhalten der Nerven in der Leber von Mensch und Säugetier. Z. mikrosk.-anat. Forsch. 14: 73-93 (1928).

Satler, J. J., S. Predan and M. Brzin: The activity and cytochemical localization of acetylcholineesterase and butyrylcholinesterase in the rat liver. Histochemistry 39: 65-70 (1974).

Sawchenko, P. E. and M. I. Friedman: Sensory functions of the liver-a review. Amer. J. Physiol. 236: R5-R20 (1979).

Shibasaki, S.: Fine structure, function and distribution of Ito cell-a review. (In Japanese). Metabolism 19: 23-32 (1982).

Skaaring, P. and F. Bierring : On the intrinsic innervation of normal rat liver. Cell Tiss. Res. 171: 141-155 (1976).

Smith, K. R., jr.: The ultrastructure of the human Haarscheibe and Merkel cell. J. Invest. Derm. 54: 150-159 (1970).

Spencer, P. S. and H. H. Schaumberg: An ultrastructural study of the inner core of the Pacinian corpuscle. J. Neurocytol. 2: 217-235 (1973).

Sutherland, Sh. D.: An evaluation of cholinesterase techniques in the study of the intrinsic innervation of the liver. J. Anat. (Lond.) 98: 321-326 (1964).

Suzuki, H. and K. Kurosumi : Fine structure of the cutaneous nerve endings in the mole snout. Arch. histol. jap. 34: 35-50 (1972).

Tanuma, Y. and T. Ito: Electron microscope study on the hepatic sinusoidal wall and fat-storing cell in the bat. Arch. histol. jap. 41: 1-39 (1978).

- : Electron microscopic study on the sinusoidal wall of the liver of the crucian, Carassius carassius, with special remarks on the fat-storing cell (FSC). Arch. histol. jap. 43: 241-263 (1980).

Tanuma, Y., M. Ohata and T. Ito: An electron microscopic study of the kitten liver with special reference to fat-storing cells. Arch. histol. jap. 44: 23-49 (1981).

—- Electron microscopic studies on the sinusoidal cells in the monky liver. Arch. histol. jap. 46: 401-426 (1983).

Tsuneki, K. and K. Ichihara: Electron microscope study of vertebrate liver innervation. Arch. histol. jap. 44: 1-13 (1981).

Ungváry, Gy. and T. Donáth: On the monoaminergic innervation of the liver. Acta anat. 72: 446-459 (1969).

Uno, H. : Catecholaminergic terminals in the perisinusoidal spaces of the hepatic acini and adrenal cortex of macaques. Anat. Rec. 187: 735 (1977).

Wake, K.: "Sternzellen" in der Leber: perisinusoidal cells with special reference to storage of vitamin A. Amer. J. Anat. 132: 429-462 (1971).

Watanabe, I. : Fine structure of lamellated nerve endings in the gingiva of man and the Cebus apella monkey. Okajimas Fol. anat. jap. 59: 181-198 (1982).

Watanabe, I. and E. Yamada: The fine structure of lamellated nerve endings found in the rat gingiva. Arch. histol. jap. 46: 173-182 (1983).

Yamada, E.: Some observations on the nerve terminal on the liver parenchymal cell of the mouse as revealed by electron microscopy. Okajimas Fol. anat. jap. 40: 663-677 (1965).

Yamamoto, Masami : Ultrastructure and function of Ito cell (fat-storing cell) in the liver. (Japanese text with English abstract). Med. J. Hiroshima Univ. 23: 245-274 (1975).

Yamamoto. M. and H. Enzan : Morphology and function of Ito cell (fat-storing cell) in the liver. Recent Adv. RES Res. 15: 54-75 (1975).

Yamamoto, Masaru: Electron microscopic studies on the innervation of the smooth muscle and the interstitial cell of Cajal in the small intestine of the mouse and bat. Arch. histol. jap. 40: 171201 (1977).

anat. jap. 57 : 159-166 (1980).

Yamamoto, T.: The fine structure of the palisade-type sensory endings in relation to hair follicles. J. Electron Microsc. 15: 158-166 (1966). 
Yamauchi, A.: Electron microscopic studies on the autonomic neuro-muscular junction in the tenia coli of the guinea pig. Acta anat. nippon. 39: 22-38 (1964).

大畑まさ子

干173 東京都板橋区加賀 2-11-1

帝京大学医学部

第一解剖学教室
Dr. Masako Ohata

Department of Anatomy

Teikyo University School of Medicine

Kaga 2-11-1, Itabashi-ku

Tokyo, 173 Japan 